Trabajo de Fin de Máster

Máster Geofísica y Meteorología

\title{
Relaciones entre el ozono troposférico, las partículas ultrafinas y los episodios de formación de partículas en Granada
}

\section{Autora: Marta Alonso Lagarda}

Tutores: Francisco José Olmo Reyes, Hassan Lyamani

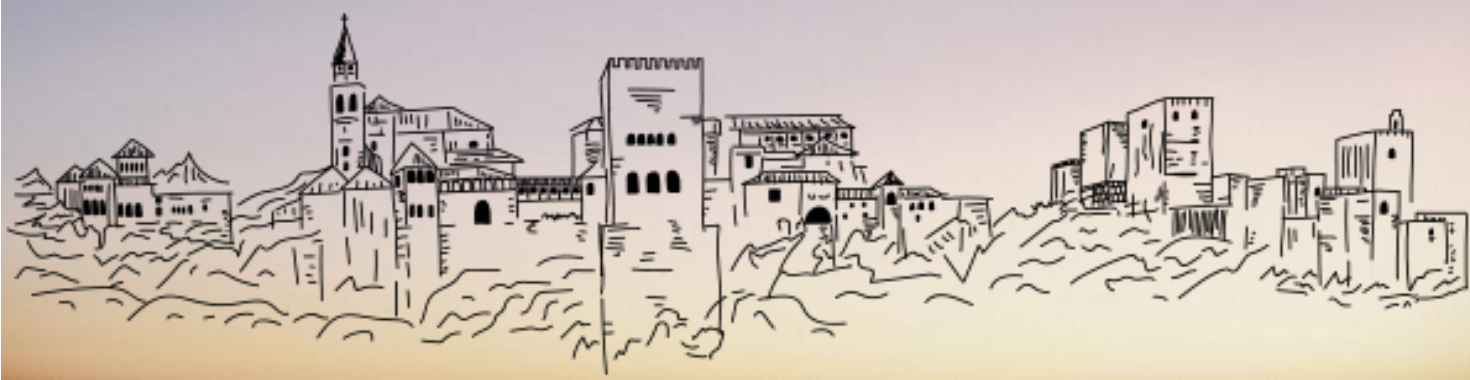




\section{Agradecimientos}

Quiero agradecer la ayuda de mis tutores Hassan y Paco, y la de Juan Andrés Casquero. A Laura, y al apoyo incondicional de José. A mis amigos, por estar ahí, y a mi familia por hacerlo posible. 


\section{Índice}

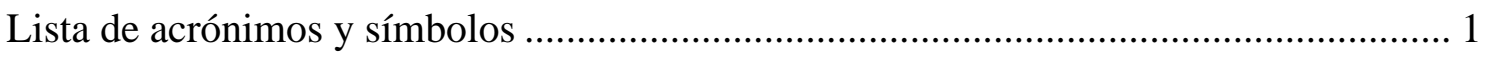

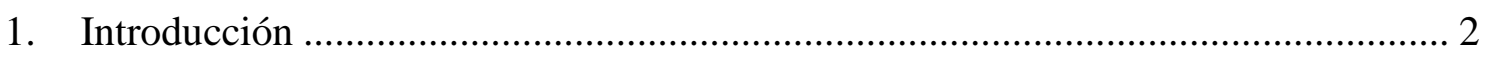

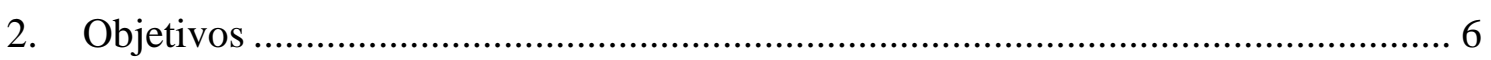

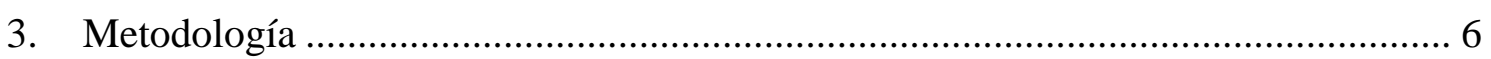

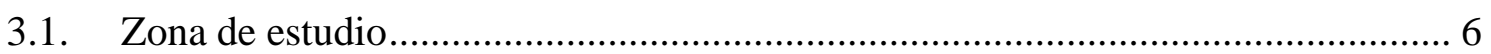

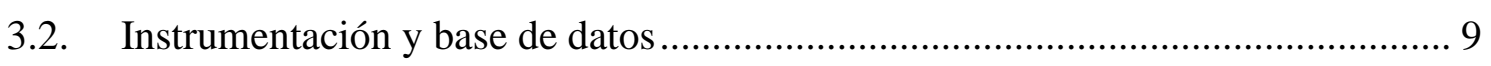

3.3. Identificación de eventos NPF y cálculo de parámetros.................................... 11

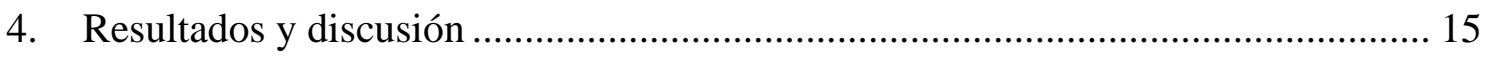

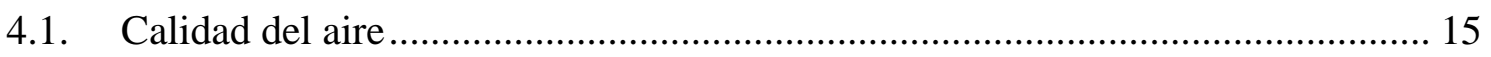

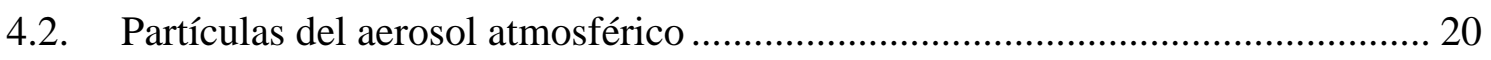

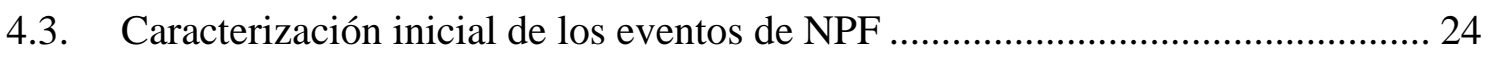

4.4. Relación de los eventos de NPF con otros parámetros....................................... 27

4.4.1. Estudio de las tasas de formación de partículas .................................................. 31

4.4.2. Estudio de las tasas de crecimiento de partículas ............................................ 33

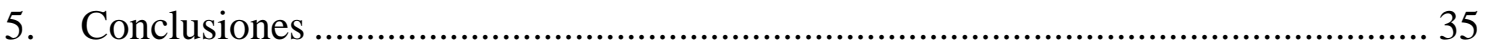

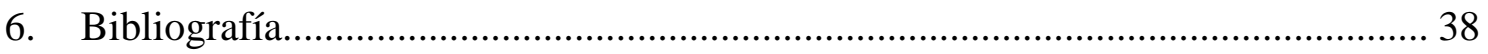




\section{Lista de acrónimos y símbolos}

- UFPs - Ultrafine Particles, partículas ultrafinas

- NPF - New Particle Formation, formación de nuevas partículas

- $\mathrm{PM}_{10}$ - Particulate Matter 10, material particulado con diámetro aerodinámico menor de $10 \mu \mathrm{m}$

- CCN - Cloud Condensation Nuclei, núcleos de condensación

- COVs - Compuestos orgánicos volátiles

- CS - Condensation Sink, sumidero de condensación

- GR - Growth Rate, tasa de crecimiento

- FR - Formation Rate, tasa de formación

- $\mathrm{N}_{\text {nuc }}$ - Concentración de partículas del modo de nucleación

- $\mathrm{F}_{\text {coag }}$ - Pérdida de partículas por coagulación

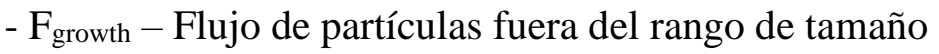

- Coag $S_{\text {nuc }}$ - Sumidero de coagulación para el modo de nucleación

- $\mathrm{D}_{\mathrm{pg}}$ - Diámetro geométrico medio

- BC - Black carbon, hollín

- UV - Ultravioleta

- SD - Standard deviation, desviación estándar

- SMPS - Scanning Mobility Particle Sizer Spectrometer, medidor de tamaño de las partículas por escaneo de su movilidad

- DMA - Differential Mobility Analizer, analizador de la movilidad diferencial

- CPC - Particle Optical Counter, contador óptico de partículas

- AGORA - Andalusian Global Observatory of the Atmosphere

- ACTRIS - Aerosol, Cloud and Trace Gasses Research Infrastructure

- REDIAM - Red de Información Ambiental de Andalucía

- IISTA-CEAMA - Instituto Interuniversitario de Investigación del Sistema Tierra en Andalucía-Centro Andaluz de Medio Ambiente

- OMS - Organización Mundial de la Salud 


\section{Introducción}

El aerosol atmosférico se define como el conjunto de partículas en suspensión en la atmósfera, en estado sólido o líquido, salvo agua pura, presente por causas naturales o antropogénicas (Mészáros, 1999). Sus diámetros suelen estar comprendidos entre los nanómetros y unos pocos centenares de micrómetros. Dichas partículas pueden ejercer una enorme influencia, por ejemplo, sobre el clima y la salud humana, cuestiones que marcan dos líneas fundamentales en las que se centran algunos de los actuales esfuerzos en investigación.

Las partículas atmosféricas interaccionan con la radiación de varias formas: pueden atenuarla, mediante la dispersión y absorción. La dispersión, más conocida por su término en inglés scattering, consiste en una redirección de la radiación, mientras que la absorción es un proceso que extrae la energía radiante y la transforma en energía interna de la partícula. Debido a estas interacciones, las partículas del aerosol atmosférico pueden modificar el balance radiativo en el sistema Tierra-Atmósfera, ejerciendo un efecto climático de forma directa y semidirecta. De manera directa, las partículas absorben y dispersan la radiación, de onda corta y larga, en diferentes proporciones dependiendo de sus características físicas y químicas. De manera semidirecta, la absorción provoca ajustes en el balance de energía, el perfil termodinámico atmosférico y la nubosidad. Ambos mecanismos constituyen el forzamiento radiativo debido a la interacción aerosolradiación ( $5^{\circ}$ Informe del IPCC).

Por otro lado, las partículas atmosféricas también interaccionan con las nubes, produciendo efectos indirectos sobre el balance radiativo. Las partículas pueden actuar como núcleos de condensación de nubes ( $\mathrm{CCN}$, Cloud Condensation Nuclei), por lo que pueden modificar la microfísica de las nubes, su albedo y vida media. Esto es lo que se conoce como el forzamiento radiativo debido a la interacción aerosol-nubes.

Además, a pesar de no estar reguladas legalmente, múltiples estudios han mostrado el potencial daño que producen las partículas ultrafinas (con diámetros menores de $0.1 \mu \mathrm{m}$ ) para la salud (p. ej., Tobías et al., 2018; Atkinson et al., 2010; Lanzinger et al., 2016). Los efectos están fuertemente relacionados con el tamaño de las partículas, ya que este factor determina de manera probabilística la capacidad de transporte y penetración de las partículas en el organismo humano, de manera que a menor diámetro de partícula más podría afectar a los sistemas respiratorio y cardiovascular.

Teniendo en cuenta sus distribuciones de tamaño, se suelen clasificar en diferentes modos (Figura 1): nucleación, Aitken, acumulación, partículas finas y gruesas (Casquero-Vera et al., 2020):

- El modo de nucleación engloba las partículas con diámetros inferiores a $25 \mathrm{~nm}$. Son partículas que se forman por procesos de nucleación de gases precursores, como se comentará posteriormente. Estos procesos dependen de la concentración de los gases precursores, de la concentración del aerosol preexistente, de la humedad relativa y de la temperatura. El límite inferior de tamaño del modo de nucleación no está bien definido, pero podría ser del orden de los 1-2 nm.

- El modo Aitken incluye las partículas en el rango de diámetros de 25-100 nm, y son partículas que suelen originarse por crecimiento de partículas del modo de nucleación como resultado de los procesos de condensación y coagulación.

- El modo de acumulación comprende las partículas en el rango de 0.1 a $1 \mu \mathrm{m}$. Estas partículas suelen formarse por coagulación de partículas más pequeñas, o 
por mecanismos de condensación de los gases atmosféricos como consecuencia de reacciones en fase líquida en las gotas de agua de las nubes.

- El modo de partículas finas suele incluir los modos de nucleación, Aitken y acumulación. Se forman en procesos de combustión o por conversión gaspartícula. Están compuestas por metales y óxidos, carbono negro o elemental, compuestos orgánicos primarios y secundarios, sulfatos, nitratos, etc.

- Finalmente, las partículas del modo grueso suelen tener tamaños superiores a $1 \mu \mathrm{m}$, y se forman por la descomposición mecánica de minerales, desechos orgánicos, materiales de la superficie terrestre. También puede incluir a la sal marina, nitratos, sulfatos y compuestos derivados de las reacciones de estos gases con partículas preexistentes (Colbeck y Lanzaris, 2014; Koulouri et al., 2008; Querol et al., 1998).

- Además, podemos destacar las mencionadas partículas ultrafinas (UFPs, Ultra Fine Particles), cuyos diámetros aerodinámicos son inferiores a $0.1 \mu \mathrm{m}$. En la normativa europea de calidad del aire también se distinguen las $\mathrm{PM}_{2.5}$ y $\mathrm{PM}_{10}$, material particulado con diámetros aerodinámicos menores a 2.5 y $10 \mu \mathrm{m}$, respectivamente.

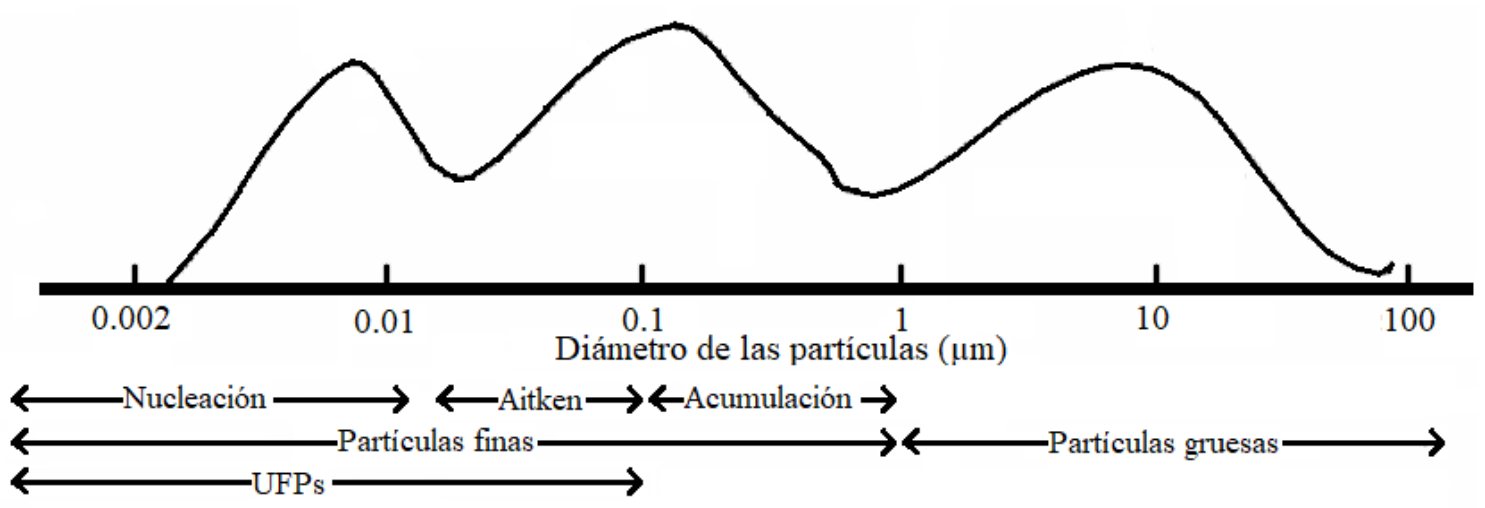

Figura 1. Esquema idealizado de la distribución de tamaños de partículas atmosféricas. Figura adaptada de Whitby et al. (1976), originalmente adaptada de Whitby y Cantrell (1976).

El origen de las partículas puede ser tanto natural como antropogénico. Por ejemplo, respecto al origen natural, podríamos considerar a las partículas de sal marina, compuestos orgánicos volátiles (COVs) procedentes de emisiones biogénicas y partículas procedentes de las intrusiones de polvo sahariano. De origen antropogénico podríamos considerar las fuentes de emisión derivadas de la actividad humana en zonas urbanas, por ejemplo las debidas al tráfico rodado (desgaste de frenos y neumáticos), la erosión y resuspensión de partículas del suelo (principalmente partículas gruesas), las procedentes de la emisión directa por la combustión de motores y la formación secundaria de partículas a partir de los gases precursores que se emiten (partículas finas), las procedentes de las quemas de biomasa y de los procesos industriales y la construcción. Un estudio reciente pone de manifiesto que una de las fuentes principales de partículas en Granada es el tráfico rodado (Titos et al., 2014), aunque también influye notablemente el polvo mineral, incluyendo el polvo sahariano y las partículas procedentes de actividades de la construcción y demolición, las quemas de biomasa, así como el aerosol procedente de otras fuentes regionales. Cabe destacar que uno de los principales contribuyentes a las partículas emitidas directamente es el hollín o black carbon, BC, 
procedente de los procesos de combustión incompleta en vehículos y los sistemas de calefacción (p. ej., Lyamani et al., 2011).

Atendiendo a los mecanismos de formación del aerosol atmosférico, la conversión gaspartícula es un proceso que se conoce como nucleación, mediante el cual gases con baja volatilidad condensan para dar lugar a gotas líquidas o incluso partículas sólidas. Las nuevas partículas recién formadas entran en el rango de tamaños menores de $0.1 \mu \mathrm{m}$, es decir, son partículas ultrafinas. Este tipo de eventos, que suele ser el resultado de reacciones fotoquímicas entre diferentes sustancias catalizadas por la radiación UV, es la NPF o New Particle Formation (Formación de Nuevas Partículas), los cuales serán la base en la que se centrará el presente trabajo.

En concreto, la NPF es un conjunto de procesos complejos que comprenden (p. ej., Kerminen et al., 2018):

- Colisión de moléculas gaseosas que quedan agregadas formando cúmulos o clusters.

- Nucleación o transformación de la materia gaseosa a su fase particulada. Los clusters nanométricos tienen tamaños entre 1 y $2 \mathrm{~nm}$.

- Crecimiento de las partículas durante varias horas hasta tamaños de 50-100 nm.

El principal gas precursor que participa en la nucleación es el dióxido de azufre, $\mathrm{SO}_{2}$ (Figura 2). Su oxidación da lugar a ácido sulfúrico, $\mathrm{H}_{2} \mathrm{SO}_{4}$, una molécula gaseosa extremadamente no volátil que, posteriormente, al acumularse, forma una molécula gigante y altamente estable debido a su alta oxidación. Ésta última es la que numerosos estudios muestran como principal responsable de la formación de nuevas partículas (p. ej., Kerminen et al., 2018).

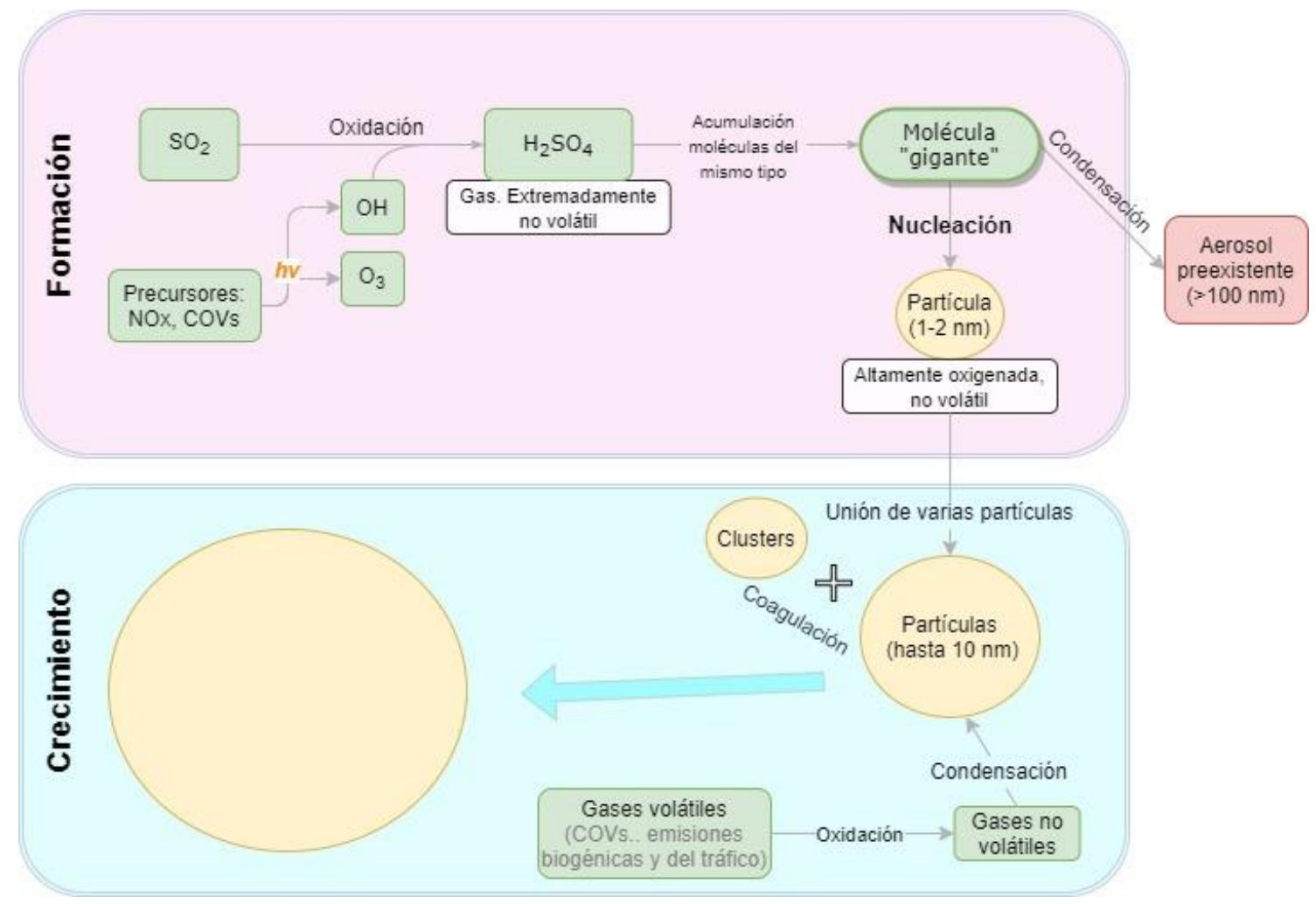

Figura 2. Esquema de la formación y crecimiento de nuevas partículas (NPF), incluyendo su relación con factores influyentes. 
La principal fuente de emisión del $\mathrm{SO}_{2}$ es antropogénica, concretamente la quema de combustibles fósiles azufrados, como por ejemplo el petróleo. También existen fuentes naturales, como las erupciones volcánicas.

Por otro lado, el ozono $\left(\mathrm{O}_{3}\right)$ es uno de los actores principales de la química atmosférica ya que, entre otros procesos, interviene en el inicio de procesos de oxidación fotoquímica, fotólisis y las subsecuentes reacciones de los subproductos para formar el radical hidroxilo $(\mathrm{OH})$. Este radical juega un papel importante en la oxidación del $\mathrm{SO}_{2}$ para llegar a formar $\mathrm{H}_{2} \mathrm{SO}_{4}$. Es por ello por lo que el ozono interviene en la NPF, tanto en la formación como en el crecimiento, porque es un potente agente oxidante de partículas. Tanto es así que diversas investigaciones muestran una relación directamente proporcional entre una mayor producción de ozono troposférico y los eventos de NPF (p. ej., Pey et al., 2009; Fernández-Camacho et al., 2010; Wonaschütz et al., 2015; Wang et al., 2016), lo cual se produce principalmente durante los meses estivales y las horas centrales del día, cuando la radiación solar es mayor. En contraste con estos estudios, que incluyen diferentes patrones estacionales, hay otros que se centran en los períodos estivales, encontrando un desfase entre la ocurrencia de picos de $\mathrm{O}_{3}$ y NPF (p. ej., Carnerero et al., 2018; Querol et al., 2018).

El ozono, además de tener origen en el transporte desde la estratosfera, es un contaminante secundario producido por la fotooxidación de compuestos orgánicos volátiles $(\mathrm{COVs})$, monóxido de carbono $(\mathrm{CO})$ y metano $\left(\mathrm{CH}_{4}\right)$, en presencia de óxidos de nitrógeno $\left(\mathrm{NO}_{\mathrm{X}}\right.$, que contabiliza $\left.\mathrm{NO}_{2}+\mathrm{NO}\right)$. Los procesos que lo eliminan de la atmosfera son la deposición seca y la destrucción química, como la titración (reacción del $\mathrm{O}_{3}$ con monóxido de nitrógeno (NO) y el consecuente consumo de $\mathrm{O}_{3}: \mathrm{NO}+\mathrm{O}_{3} \rightarrow \mathrm{NO}_{2}$ $+\mathrm{O}_{2}$ ) y las reacciones catalizadas por halógenos. Sus picos de formación se dan, por tanto, en presencia de altas concentraciones de los compuestos precursores (p. ej., Monks et al., 2015) y en condiciones favorables de radiación solar incidente.

La intervención de los óxidos de nitrógeno en la producción de ozono y, a su vez, el hecho de ser compuestos con propiedades oxidativas, hace que adquieran también suma importancia en los procesos de formación y crecimiento de nuevas partículas. El origen del $\mathrm{NO}_{2}$ tiene que ver, en parte, con incendios forestales, tormentas y procesos biológicos de descomposición natural de nitratos orgánicos, etc., pero su presencia en las ciudades se debe en su mayoría a la contaminación producida por actividades antrópicas como el tráfico. El NO que se genera durante la combustión de los motores, principalmente los diésel, se oxida posteriormente a $\mathrm{NO}_{2}$. También son fuentes de emisión determinadas industrias y los sistemas de calefacción, siendo en el caso de Granada el principal responsable el tráfico rodado (Casquero-Vera et al., 2019). Cabe mencionar que el $\mathrm{NO}_{2}$ también se forma de manera secundaria como consecuencia de reacciones químicas entre el $\mathrm{NO}$ y $\mathrm{O}_{3}$, cuya contribución a la concentración total de $\mathrm{NO}_{2}$ llega a ser hasta del $75 \%$ en Granada (Casquero-Vera et al., 2019).

Otro factor clave que también influye en la formación de nuevas partículas es el hecho de que los compuestos gaseosos no volátiles, potencialmente nucleables, puedan también condensar sobre las superficies de las partículas preexistentes e inhibir la formación de partículas nuevas. Esto se cuantifica mediante los sumideros de condensación, en adelante mencionados como CS (Condensation Sink), que hacen referencia a la frecuencia con la que las moléculas gaseosas condensan en dichas partículas preexistentes.

En cuanto a las condiciones meteorológicas, se ha observado una baja humedad relativa media en los días de NPF en comparación con los días donde no se producen estos 
eventos, siendo la insolación determinante en este proceso (p. ej., Dada et al., 2017; Salma et al., 2016).

La NPF depende por tanto del balance entre la tasa de formación de nuevas partículas, lo que incluye la disponibilidad de gases precursores y condiciones meteorológicas favorables, así como de la tasa de pérdida, en términos de sumideros de condensación. Por ejemplo, en áreas con baja concentración de gases precursores se necesitará una atmósfera limpia, es decir, con baja carga de partículas preexistentes, para que las tasas de pérdida no superen las tasas de formación (p. ej., Boy and Kulmala, 2002).

Las observaciones realizadas de eventos de NPF en diversos entornos a lo largo de todo el mundo han demostrado la gran frecuencia con que se producen (p. ej., Kulmala et al., 2004). También se observan variaciones sustanciales en las escalas espaciales e intensidades de estos fenómenos: pueden darse regionalmente, a lo largo de cientos o miles de kilómetros, o en zonas concretas en forma de explosiones (bursts), como a lo largo de una costa. Es muy probable que la NPF constituya una fuente tan importante de partículas que puedan incluso llegar a dominar la concentración en número de fondo regional y en la troposfera global (p. ej., Spracklen et al., 2006; Yu et al., 2010; Gordon et al., 2017). Típicamente, estos procesos son diurnos.

La caracterización de la NPF se lleva a cabo mediante dos parámetros (Kulmala et al., 2012): la tasa de formación de partículas y la tasa de crecimiento, que se especificarán posteriormente en el apartado de Metodología.

\section{Objetivos}

El objetivo principal de este trabajo es analizar la relación de los eventos de NPF y parámetros como el ozono troposférico en la ciudad de Granada. Para ello se proponen los siguientes objetivos específicos:

- Caracterización de los parámetros de calidad del aire y análisis de sus evoluciones: anual, semanal y diaria.

- Caracterización de la fracción fina de partículas y su relación con los parámetros de calidad del aire.

- Análisis de la ocurrencia de episodios de NPF.

- Determinación de los parámetros que influyen en la formación y en el crecimiento de nuevas partículas.

\section{Metodología}

\subsection{Zona de estudio}

La zona de estudio se localiza en Granada, una ciudad del sureste de la Península Ibérica emplazada en la parte oriental de una de las depresiones del surco Intrabético y que, por su situación rodeada de montañas de entre 1000 y casi 3400 m s.n.m. (ver Figura 3), se ve frecuentemente condicionada por inversiones térmicas, principalmente en invierno. Además, desde un punto de vista meteorológico, es habitual el predominio de un intenso anticiclón de las Azores, lo que produce una situación caracterizada por vientos débiles, subsidencia y estabilidad atmosférica, que a su vez conlleva una disminución del intercambio de masas de aire entre la troposfera libre y la capa límite planetaria. La zona 
de estudio se encuentra a unos $50 \mathrm{~km}$ de la cuenca mediterránea y, por su cercanía al continente africano, a unos $200 \mathrm{~km}$ aproximadamente, se ve afectada con frecuencia por intrusiones de polvo sahariano (p. ej., Lyamani et al., 2005a, 2006a; Olmo et al., 2006, 2008; Valenzuela et al., 2012b).

El clima que prevalece, continental mediterráneo, se caracteriza por una marcada amplitud térmica estacional de inviernos fríos y veranos calurosos, siendo la diferencia diaria de temperatura también grande, llegando a superar incluso los $20^{\circ} \mathrm{C}$. Las precipitaciones se producen principalmente entre finales de otoño y principios de primavera, mientras que los veranos son secos. Situaciones de estabilidad atmosférica y lluvias escasas dificultan la limpieza de contaminantes, acumulándose por ende en la atmósfera baja. La baja humedad relativa, sobre todo en la estación seca, favorece la sequedad del terreno y la resuspensión de partículas.

La ciudad de Granada es de tamaño medio, con alrededor de 232.000 habitantes, y 534.000 habitantes si se tiene en cuenta su área metropolitana. Destaca por un denso tráfico, mientras que no tiene grandes industrias contaminantes. Las principales fuentes de partículas locales se asocian por tanto al tráfico rodado, a los sistemas de calefacción, a las quemas de biomasa y a la resuspensión de las partículas del suelo (p. ej., Lyamani et al., 2011; Titos et al., 2014). Además, Granada se ve afectada por contaminantes antropogénicos europeos (p. ej., Rodríguez et al., 2001) y por el aporte de polvo mineral procedente del norte de África.

En este estudio se han utilizado dos estaciones experimentales de medida ubicadas en la ciudad de Granada, y los registros corresponden al año 2017. Una de ellas está ubicada en el Instituto Interuniversitario de Investigación del Sistema Tierra en Andalucía (IISTA-CEAMA). Esta estación, localizada en la parte sur de la ciudad (Figura 3) y considerada como una estación de fondo urbano $\left(37.16^{\circ} \mathrm{N}, 3.58^{\circ} \mathrm{W}, 680 \mathrm{~m}\right.$ s.n.m. $)$, a 500 $\mathrm{m}$ de la autovía A-44 de circunvalación, es parte del proyecto de infraestructura europeo ACTRIS (Aerosol, Cloud and Trace Gasses Research Infrastructure, http://actris.eu; Pandolfi et al., 2018), y está incluida en el observatorio AGORA (Andalusian Global Observatory of the Atmosphere). La toma de muestras de partículas se realiza desde el tejado del edificio, a unos $15 \mathrm{~m}$ del suelo, por medio de un tubo de acero inoxidable de 5 $\mathrm{m}$ de longitud y $20 \mathrm{~cm}$ de diámetro.

La segunda estación $\left(37.16^{\circ} \mathrm{N}, 3.60^{\circ} \mathrm{W}, 666 \mathrm{~m}\right.$ s.n.m.), clasificada también como de fondo urbano, es una estación de la Red de Vigilancia de la Calidad del Aire de la Consejería de Medio Ambiente de la Junta de Andalucía (REDIAM), situada a unos $50 \mathrm{~m}$ de las vías de circulación y a $1 \mathrm{~km}$ del IISTA-CEAMA. Las medidas se realizan desde una altura de $4 \mathrm{~m}$ del suelo, situándose los instrumentos dentro de una cabina de muestreo. 

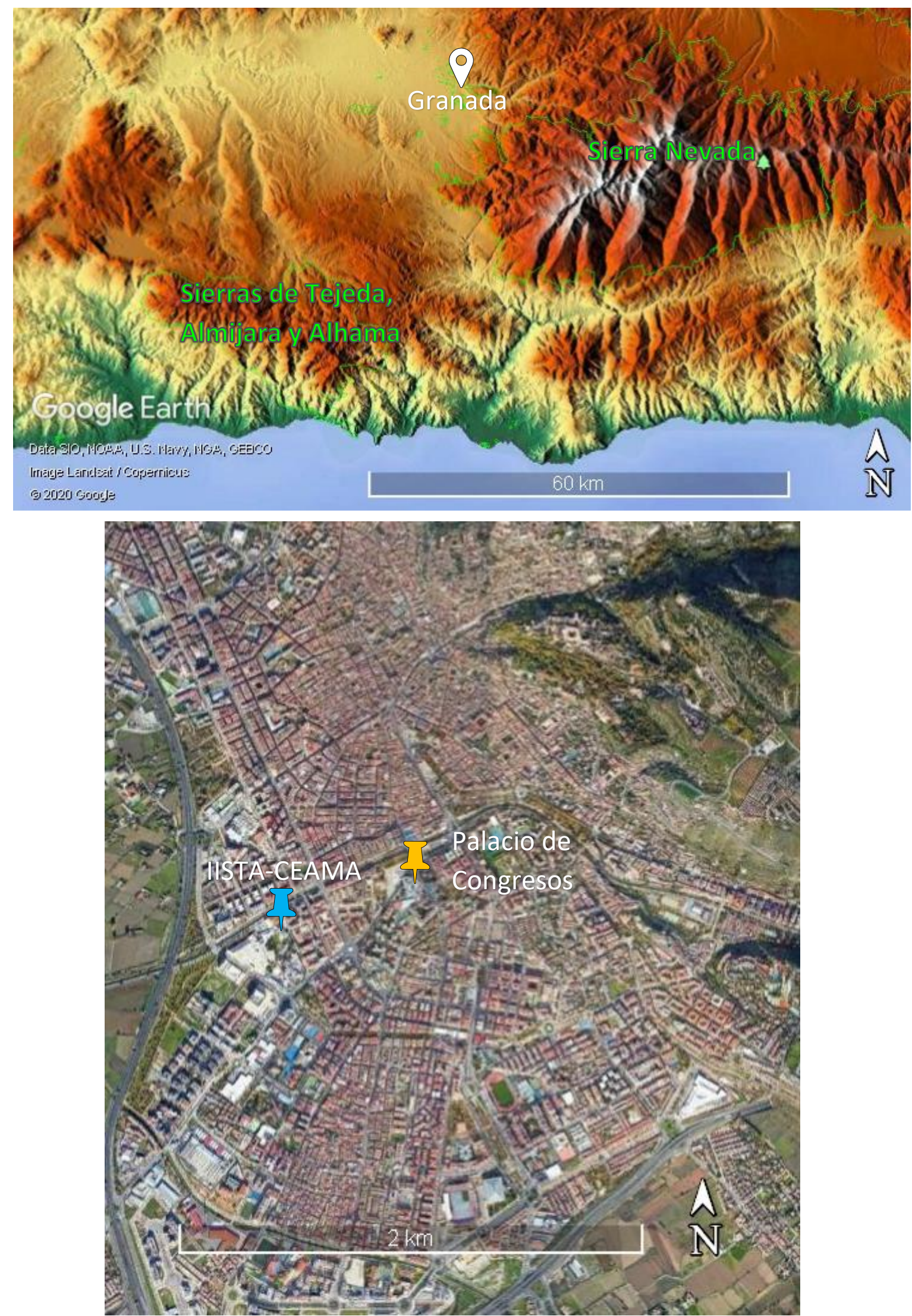

Figura 3. Arriba, mapa topográfico de la zona de estudio; abajo, localización de las estaciones de muestreo: IISTA-CEAMA y Palacio de Congresos. Fuente: Google Earth. 


\subsection{Instrumentación y base de datos}

Para la obtención de la distribución numérica de tamaño de la fracción fina de las partículas del aerosol atmosférico se utilizó, en el IISTA-CEAMA, un espectrómetro SMPS (Scanning Mobility Particle Sizer), que utiliza el principio de movilidad eléctrica para la detección y cuyo rango de diámetros es de 12 a $500 \mathrm{~nm}$. Este instrumento consta de una fuente radiactiva de rayos X que provoca la carga de las partículas, un analizador de la movilidad diferencial (DMA, Differential Mobility Analizer, TSI Modelo 3082) para clasificarlas según su tamaño y un contador de partículas (CPC, Particle Optical Counter, TSI modelo 3772). La incertidumbre de la concentración medida por el espectrómetro es de $\pm 10 \%$ para el rango de tamaños de 20 a $200 \mathrm{~nm}$, y aumenta al $30 \%$ para tamaños superiores (Wiedensohler et al., 2012).

Respecto al funcionamiento del SMPS (Figura 4), una muestra de aire con partículas se introduce en el instrumento, con un caudal de $11 \cdot \mathrm{min}^{-1}$. Se desechan aquellas mayores a un determinado tamaño mediante un impactador. La muestra seleccionada que entra en el sistema se somete en el neutralizador a una carga controlada de iones, positivos y negativos, mediante una fuente radiactiva de $\mathrm{Kr}-85$. Posteriormente las partículas cargadas pasan a la DMA, la cual dispone de dos electrodos cilíndricos concéntricos. Mediante la aplicación de una determinada diferencia de potencial, de modo que las partículas queden sujetas a un campo eléctrico, se produce una discriminación de partículas a la salida del DMA según su movilidad eléctrica (parámetro que expresa la habilidad de una partícula para atravesar un campo eléctrico, y depende inversamente de su tamaño). Un barrido de potencial escanea todo el rango de diámetros $(12-500 \mathrm{~nm})$ y se clasifican las partículas según su tamaño. Posteriormente las partículas entran en el CPC, que se compone a su vez de varias zonas: una cámara a temperatura de $35^{\circ} \mathrm{C}$ con vapor de butanol, más otra a una temperatura inferior de $10^{\circ} \mathrm{C}$, la cual provoca que el butanol se condense sobre la superficie de cada partícula de aerosol, con el fin de aumentar el tamaño a $1 \mu \mathrm{m}$ y ser detectado por técnicas ópticas. Finalmente, las partículas atraviesan una cámara óptica, donde un haz láser interacciona con ellas, y la dispersión de luz provocada se detecta por un fotodetector, que convierte la señal en pulsos eléctricos, contando el número de partículas según rangos de tamaño. 


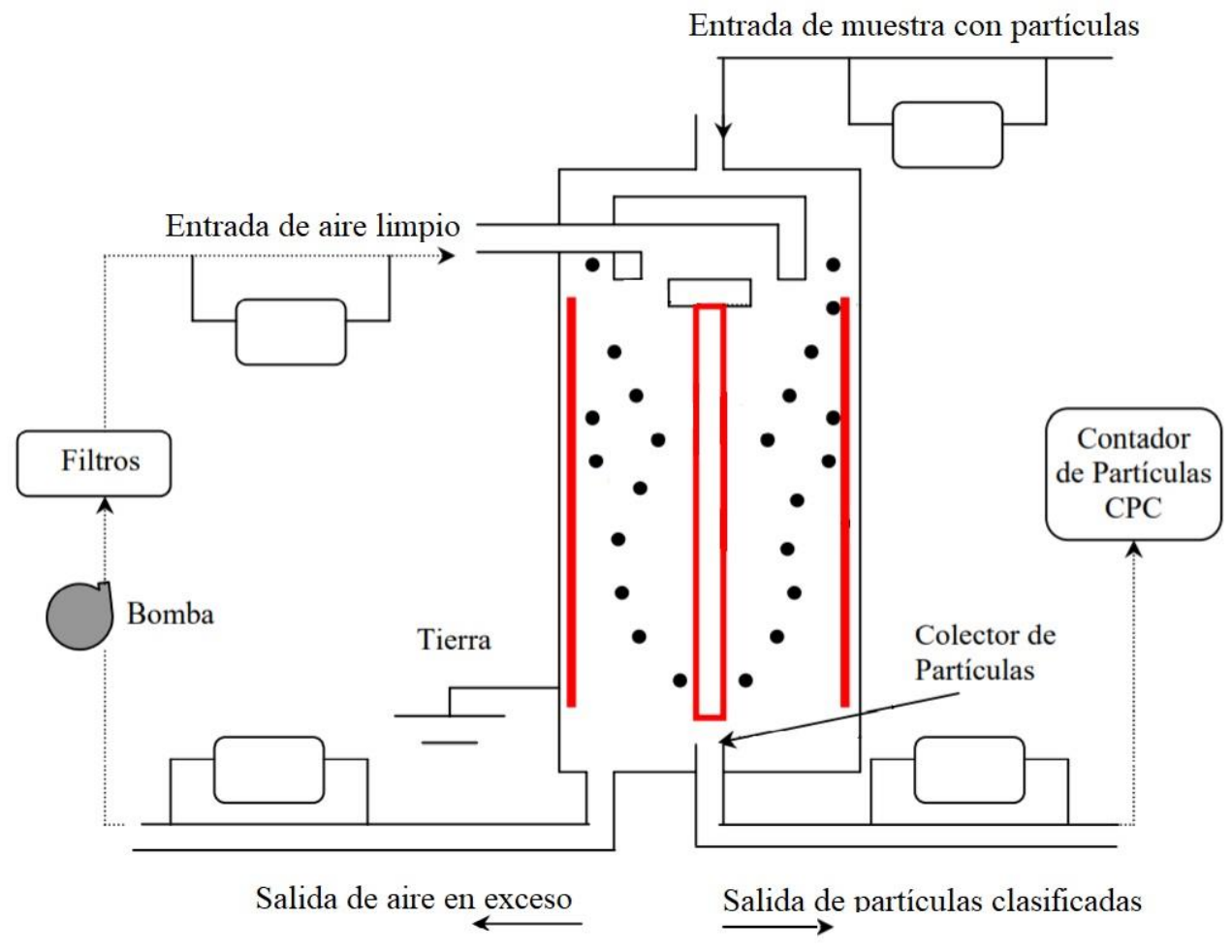

Figura 4. Esquema del funcionamiento del DMA. Las líneas rojas representan los electrodos. Figura adaptada de Sorribas (2007).

El SMPS midió de manera automática y de forma continua la concentración de partículas en número $\cdot \mathrm{cm}^{-3}$ durante el año 2017 , con una resolución temporal de 5 minutos. La base de datos obtenida tuvo lagunas debido a problemas técnicos, por lo que del total de medidas que se tomaron, 105119, el 13\% de ellas fueron descartadas (13602 datos), disponiéndose finalmente de datos válidos en 332 días.

Para este estudio se consideraron tres modos de la distribución de tamaños: el modo de nucleación, de 12 a 25 nm; el modo Aitken, 25-100 nm; y el modo de acumulación, 100$500 \mathrm{~nm}$. La concentración total de partículas es la suma de los tres modos, mientras que el modo de las partículas ultrafinas es la suma de los modos de nucleación y Aitken.

La concentración másica de los gases $\mathrm{SO}_{2}, \mathrm{NO}_{2}$ y $\mathrm{O}_{3}$ y el material particulado atmosférico $\left(\mathrm{PM}_{10}\right)$, registrados en la estación de calidad del aire (red REDIAM), se midieron mediante analizadores de la firma Thermo Environmental Instruments Inc. La estación de medida registró datos automáticamente en períodos de 10 minutos, en $\mu \mathrm{g} \cdot \mathrm{m}^{-3}$.

$\mathrm{El} \mathrm{SO} 2$ se obtiene por el método de fluorescencia de ultravioleta (UV). La muestra de aire recogida se introduce en una cámara de reacción, donde se excita mediante una fuente de radiación UV. El SO $\mathrm{SO}_{2}$ excitado emite radiación UV a un rango de longitud de onda mayor al volver a un estado de menor energía, cuya intensidad recogida por el fotodetector es proporcional al número de moléculas de $\mathrm{SO}_{2}$.

El $\mathrm{NO}_{2}$ es analizado junto con $\mathrm{NO}$ y NOx por quimioluminiscencia, mediante el Thermo Environmental Instruments Inc, Modelo 42. Con esta técnica la muestra es introducida en el instrumento de medida, y un sistema de válvula permite el paso de los gases a través de dos cámaras. En una de ellas, la cámara de reacción, se mezcla con un flujo constante de $\mathrm{O}_{3}$. El NO y $\mathrm{O}_{3}$ reaccionan, produciendo $\mathrm{NO}_{2}$ excitado y $\mathrm{O}_{2} . \mathrm{El} \mathrm{NO} \mathrm{N}_{2}$, al pasar a su estado no excitado, emite radiación IR (600-3000 nm), siendo la intensidad detectada proporcional a la concentración de NO. En la otra cámara, un convertidor catalítico reduce 
el $\mathrm{NO}_{2}$ a $\mathrm{NO}$ para realizar posteriormente la misma reacción comentada con el $\mathrm{O}_{3}$, siendo en esta ocasión la radiación IR detectada la equivalente a la concentración de $\mathrm{NOx}$. El $\mathrm{NO}_{2}$ se obtiene por tanto de manera indirecta, por diferencia entre NOx y NO.

El analizador Thermo Environmental Instruments Inc. Modelo 49 se utiliza para muestrear el $\mathrm{O}_{3}$, mediante fotometría UV. Con esta técnica se aprovecha la absorción de radiación UV (tiene un máximo en $254 \mathrm{~nm}$ ) para determinar, por la Ley de Beer-BouguerLambert, la concentración de ozono, la cual es proporcional a dicha absorción. El sistema consta de una célula de absorción en la que se suministra alternativamente aire muestreado con ozono y aire muestreado libre de ozono, previo tratamiento en un convertidor catalítico.

Para obtener las muestras de $\mathrm{PM}_{10}$ se ha utilizado un captador de absorción de radiación beta (Thermo Environmental Instruments Inc). Se introduce en el instrumento un flujo constante de aire y se filtra con un cabezal de $\mathrm{PM}_{10}$ para eliminar aquellas partículas con tamaños superiores a $10 \mu \mathrm{m}$, para posteriormente retener las partículas en un filtro y exponerlas a un haz de radiación beta. Una cámara de ionización detecta la atenuación de radiación beta tras pasar por dicho filtro, lo que se relaciona con la masa de partículas.

Los registros de los distintos parámetros en la estación de calidad del aire también se filtraron para descontar errores en las medidas. Finalmente, tras este análisis, las medidas disponibles respecto al total de 2017 fueron el 82, 93, 97 y 98\% de las medidas de $\mathrm{SO}_{2}$, $\mathrm{NO}_{2}, \mathrm{O}_{3}$ y $\mathrm{PM}_{10}$, respectivamente. No obstante, teniendo en cuenta el porcentaje de días en los que ocurrieron eventos de formación de nuevas partículas, no fue posible contar con datos de calidad del aire en el $40 \%$ de los casos para el $\mathrm{SO}_{2}$, en el $21 \%$ para el $\mathrm{NO}_{2}$, y en un $7 \%$ de casos para el $\mathrm{O}_{3}$. En el caso de las medidas de $\mathrm{PM}_{10}$ se contó con todos los registros en estos eventos.

\subsection{Identificación de eventos NPF y cálculo de parámetros}

La identificación de eventos de formación de nuevas partículas se realizó de manera visual, teniendo en cuenta las evoluciones temporales de las distribuciones de tamaño de partículas observadas, siguiendo las pautas de Dal Maso et al. (2005). En este sentido, para esta identificación, debe aparecer de manera clara un nuevo modo de partículas de nucleación en el rango de tamaños entre 12 y $25 \mathrm{~nm}$. Hay que destacar que el diámetro de las partículas recién formadas llega a ser de 1 o $2 \mathrm{~nm}$, pero se utiliza el límite de detección del instrumento. Dicho modo debe permanecer durante horas y mostrar signos de crecimiento. De esta manera quedan excluidos los fenómenos de producción de partículas de fuentes puntuales, ya que solo son de interés los NPF regionales. Estas condiciones se reconocen mediante formas de "banana" en las evoluciones temporales de la distribución de tamaño, como se muestra a modo de ejemplo en la Figura 5, donde se recogen 3 días tipo: uno con evento, otro sin evento, y otro que podríamos clasificar como indefinido. Como se puede observar en el primer gráfico, en los días con eventos aparece, en este caso desde las 10:00 h, una mayor concentración de partículas finas que crece, dando visualmente esa característica forma de "banana". 

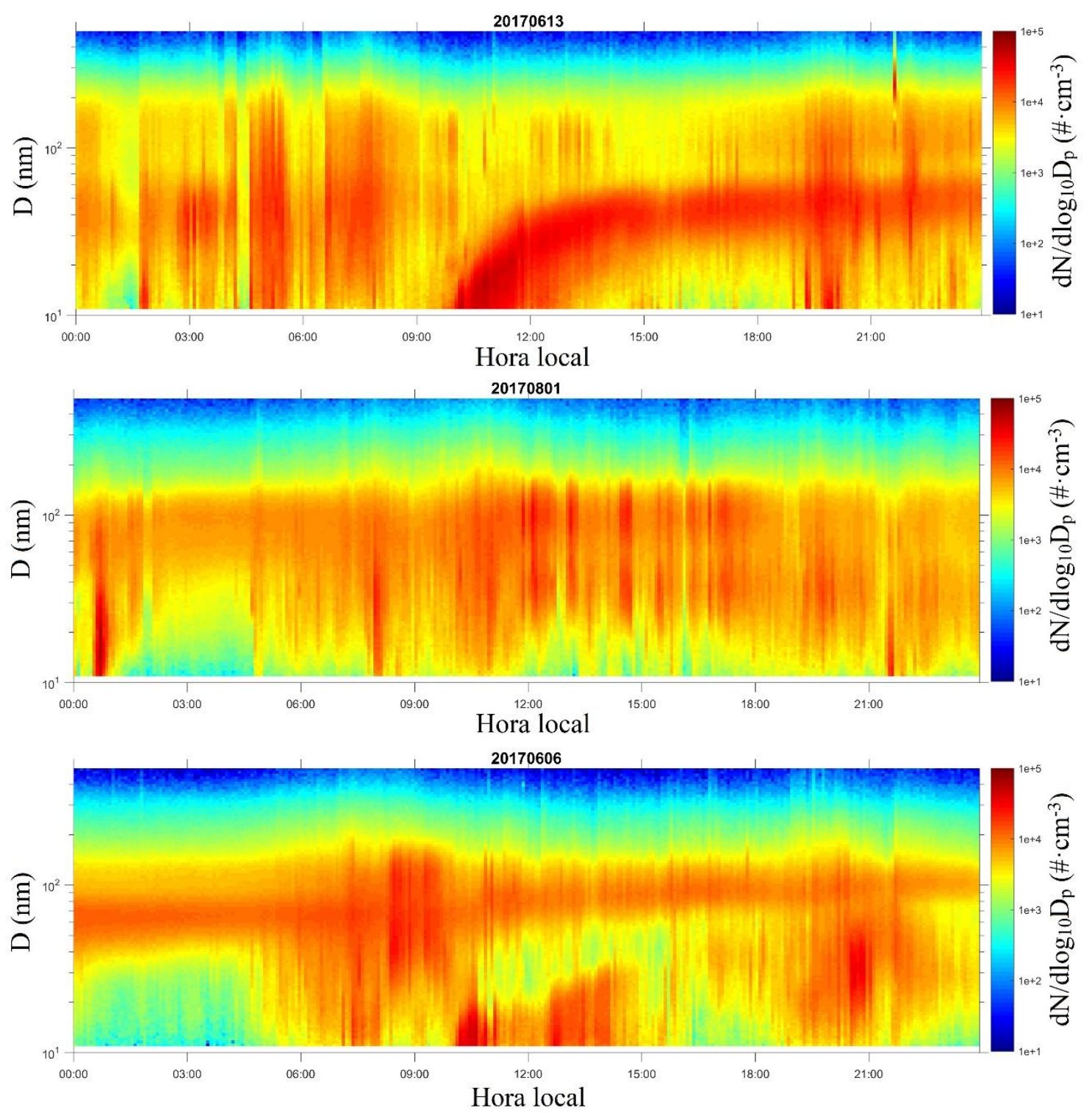

Figura 5. De arriba abajo, ejemplos de día de evento de NPF, día sin evento y día indefinido.

Un esquema de este procedimiento de identificación se muestra en la Figura 6. 


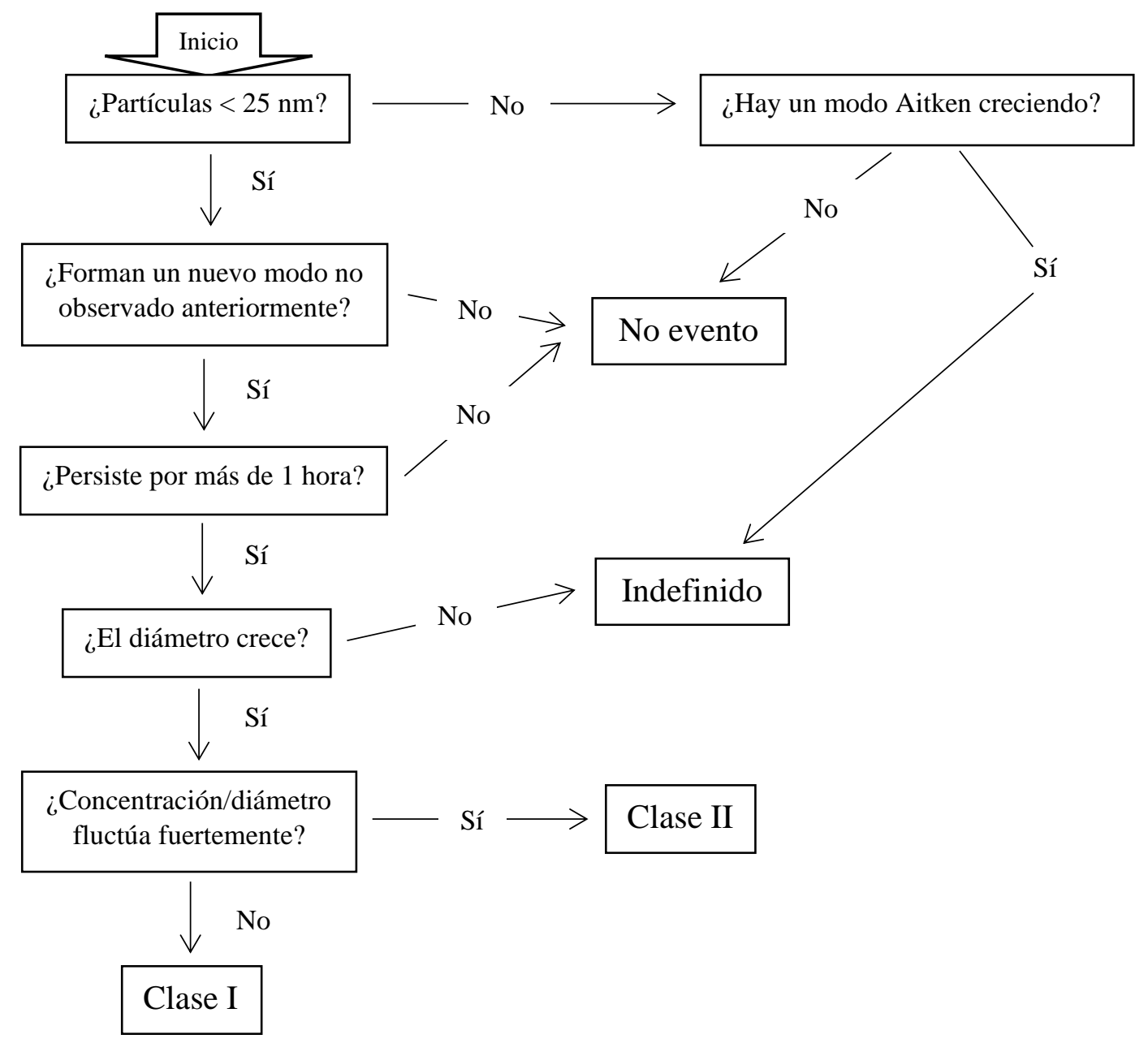

Figura 6. Esquema de la clasificación de los eventos de NPF. Adaptado de Dal Maso et al. (2005).

En nuestro estudio, la clasificación de los eventos se ha realizado del siguiente modo:

- Clase I: la evolución de la distribución de tamaños se comporta bien, esto es, que los parámetros derivados GR (tasa de crecimiento) y FR (tasa de formación) pueden determinarse con un buen nivel de confianza estadístico.

- Clase II: los parámetros GR y FR no pueden determinarse o tienen un nivel de confianza estadístico bajo.

- No eventos: ausencia de partículas en el modo de nucleación.

- Indefinidos: no cumplen los criterios para ser incluidos en días de eventos (clase I o II) o sin eventos. Se observa la ocurrencia esporádica del modo de nucleación, o el crecimiento sólo en tamaños mayores.

Hemos utilizado los días con eventos y sin eventos para estudiar la relación entre la NPF y los parámetros de calidad del aire. Los días caracterizados como indefinidos no los hemos utilizado en nuestro análisis.

Tal y como hemos comentado anteriormente, los eventos de formación de nuevas partículas se caracterizan mediante dos parámetros (Kulmala et al., 2012): la tasa de crecimiento y la tasa de formación de partículas. Además, los procesos de condensación y coagulación se cuantifican mediante los sumideros de condensación y coagulación, respectivamente. Así, podemos describir estos parámetros como: 
-Tasa de crecimiento de partículas o Growth Rate, GR $\left(\mathrm{nm} \mathrm{h}^{-1}\right)$ : ritmo al que crecen hasta alcanzar tamaños mayores. Para determinarla se utiliza el cambio temporal del diámetro geométrico medio $\left(\mathrm{D}_{\mathrm{pg}}\right)$ del modo de nucleación (ver Ecuación 1). Esto se obtiene como resultado de realizar un ajuste automático log-normal a la distribución modal de tamaños medida durante un evento de formación de partículas. El método, desarrollado por la Universidad de Helsinki (Hussein et al., 2005), realiza un análisis de mínimos cuadrados para ajustar 2 o 3 modos y devuelve los parámetros de los modos log-normales (Figura 7).

$$
G R=\frac{\Delta D_{p g}}{\Delta t}
$$

Ecuación 1

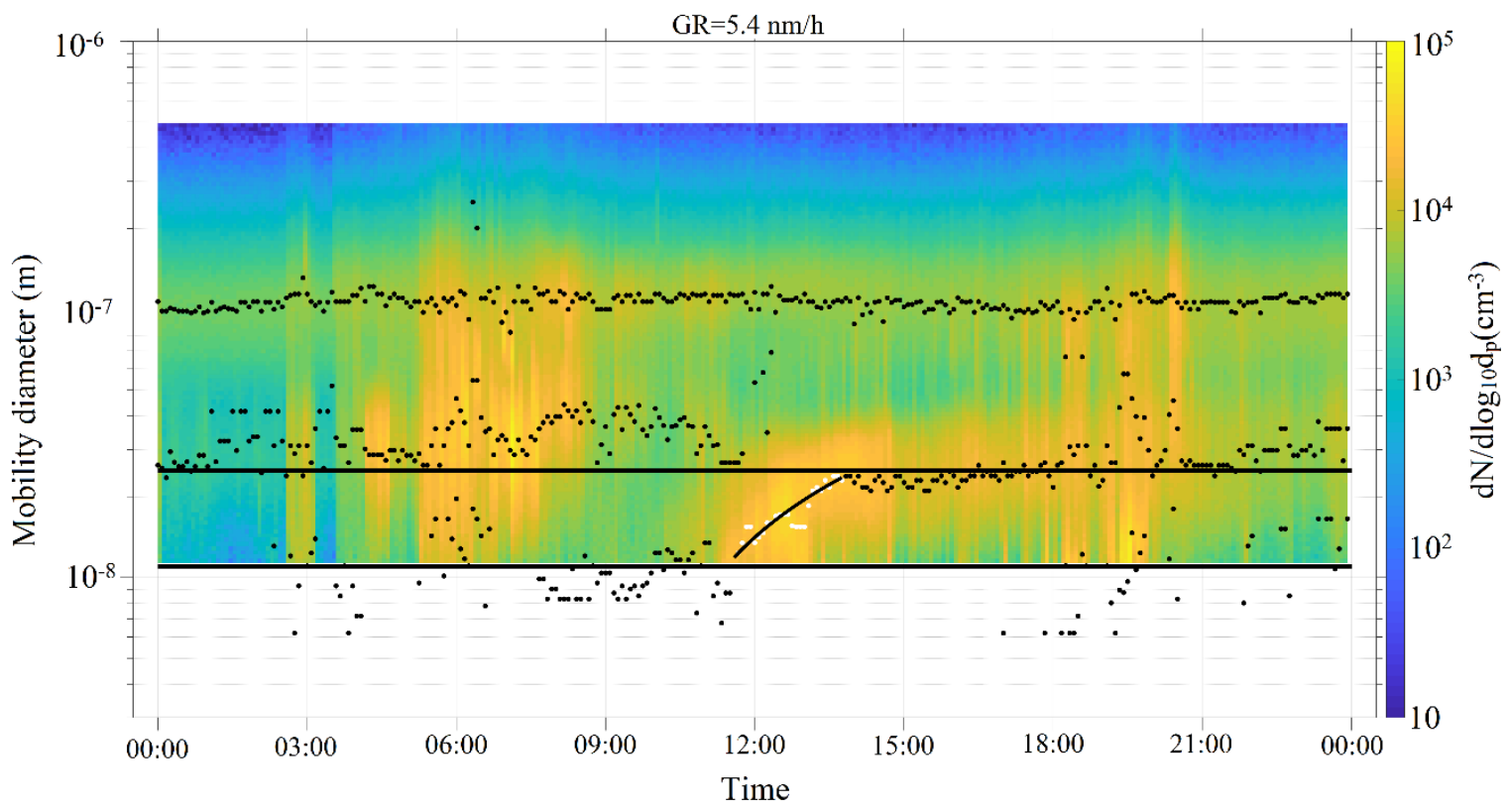

Figura 7. Ejemplo de un análisis de la evolución temporal de la distribución de tamaños de partículas. Los puntos blancos representan los tamaños geométricos medios ajustados, y la línea negra es la recta de ajuste. Las líneas negras horizontales marcan el rango de tamaños correspondiente al modo nucleación (12-25 nm).

-Tasa de formación de partículas o Formation Rate, FR $\left(\mathrm{cm}^{-3} \mathrm{~s}^{-1}\right)$ : ritmo al que se forman nuevas partículas. Este parámetro es más difícil de obtener, puesto que la aparición de partículas por debajo del tamaño límite de detección de los instrumentos no nos permite cuantificarlas. Por tanto, se calculan para tamaños desde diámetros de $12 \mathrm{~nm}$, y se asume una fuente de partículas constante que está activa durante un período de tiempo $\left[\mathrm{t}_{1 \text {,inicial }}, \mathrm{t}_{1, \text { final }}\right]$. Las partículas producidas aparecen entonces en el rango de tamaños observable entre el tiempo [ $\left.\mathrm{t}_{2, \text { inicial }}, \mathrm{t}_{2, \text { final }}\right]$, donde la diferencia $\left[\mathrm{t}_{2}\right.$,inicial $\left.-\mathrm{t}_{1 \text {,inicial }}\right]$ depende de la tasa de crecimiento de las partículas recién formadas. Durante este tiempo, una parte de estas partículas se pierde debido a procesos de coagulación (Dal Maso et al., 2005). El flujo de partículas en el rango de tamaños observable, $\mathrm{J}_{\text {nuc }}$, se puede calcular a partir de la siguiente ecuación (Kulmala et al., 2004):

$$
F R=J_{n u c}=\frac{d N_{\text {nuc }}}{d t}+F_{\text {coag }}+F_{\text {growth }}
$$

Ecuación 2

Donde $\mathrm{N}_{\text {nuc }}$ es la concentración de partículas del modo de nucleación, $\mathrm{F}_{\text {coag }}$ se refiere a la pérdida de partículas debida a la coagulación, y $F_{\text {growth }}$ es el flujo de partículas fuera del 
rango de tamaños. Para calcular $\mathrm{N}_{\text {nuc }}$ se ajusta una recta polinómica de primer orden al incremento de la concentración de partículas del modo de nucleación. $\mathrm{F}_{\text {coag }}$ se calcula mediante la siguiente Ecuación 3:

$$
F_{\text {coag }}=\operatorname{Coag}_{n u c} \cdot N_{\text {nuc }}
$$

Ecuación 3

donde $\mathrm{CoagS}_{\mathrm{nuc}}$ es el sumidero de coagulación para el modo de nucleación, expresado como:

$$
\operatorname{CoagS}\left(D_{p}\right)=\int K\left(D_{p}^{\prime}, D_{p}\right) n\left(D_{p}^{\prime}\right) d D_{p}^{\prime}
$$

Ecuación 4

donde $\mathrm{K}$ es el coeficiente de coagulación de partículas con tamaños $\mathrm{D}_{\mathrm{p}} \mathrm{y} \mathrm{D}_{\mathrm{p}}$, calculado usando la fórmula de Fuchs (1964).

El sumidero de condensación se define como (Kulmala et al., 2001; Dal maso et al., 2005):

$$
C S=2 \pi D \int D_{p} \beta_{m}\left(D_{p}\right) n\left(D_{p}\right) d D_{p}=2 \pi D \Sigma_{i} \beta_{m}\left(D_{p, i}\right) D_{p, i} N_{i}
$$

Ecuación 5

siendo $\mathrm{D}_{\mathrm{p}, \mathrm{i}}$ el diámetro de la partícula de tamaño $i, \mathrm{y} \mathrm{N}_{\mathrm{i}}$ es la concentración de partículas en $i$; $\mathrm{D}$ es el coeficiente de difusión de vapores condensables (se asume con propiedades similares al ácido sulfúrico, $0.104 \mathrm{~cm}^{2} \mathrm{~s}^{-1}$ (Kanawade et al., 2011); y $\beta_{\mathrm{m}}$ es el factor de corrección del régimen de transición de Fuchs y Sutugin (1970).

\section{Resultados y discusión}

\subsection{Calidad del aire}

En la Figura 8 mostramos la evolución mensual de las concentraciones de $\mathrm{NO}_{2}, \mathrm{SO}_{2}, \mathrm{O}_{3}$ y $\mathrm{PM}_{10}$ medidos durante 2017 en la estación de calidad del aire de Palacio de Congresos. 

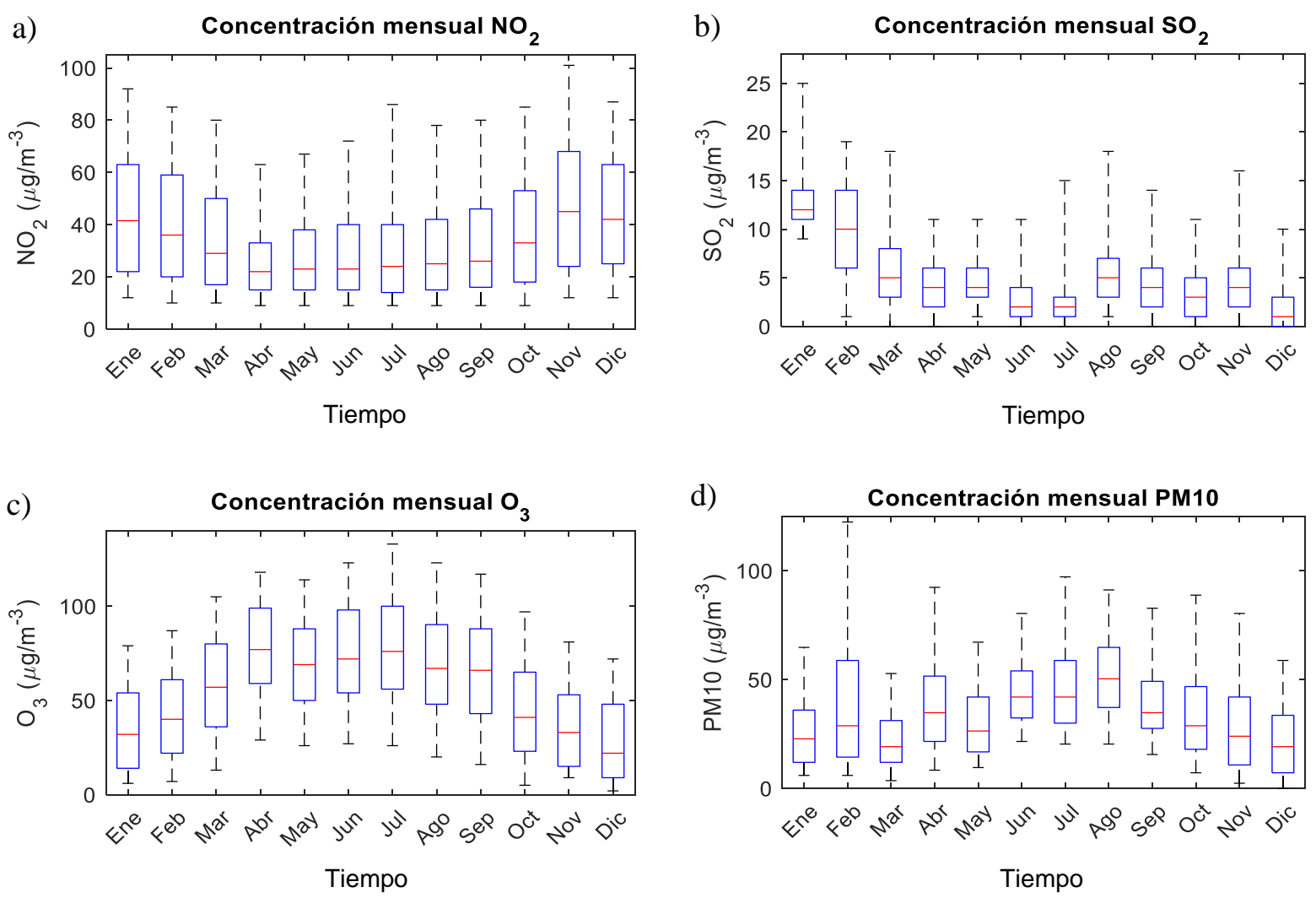

Figura 8. Evolución de la concentración mensual de: a) $\mathrm{NO}_{2}$, b) $\mathrm{SO}_{2}$, c) $\mathrm{O}_{3}$ y d) $\mathrm{PM}_{10}$; medidos en $\mu \mathrm{g} / \mathrm{m}^{-3}$ durante el año 2017. Los límites de las cajas representan los percentiles 25 y 75; los de los diagramas, los percentiles 5 y 95; las líneas rojas se corresponden con las medianas.

En la Tabla 1 se presentan algunos de los valores límites establecidos para los diferentes gases y $\mathrm{PM}_{10}$ que marca la Directiva Europea 2008/50/CE relativa a la calidad del aire ambiente en Europa, así como los valores límites recomendados por la Organización Mundial de la Salud (OMS), los que podemos comparar someramente con nuestros resultados.

Tabla 1. Algunos de los valores límites establecidos por la Directiva 2008/50/CE y los recomendados por la OMS.

\begin{tabular}{|l|l|l|l|}
\hline \multicolumn{2}{|l|}{} & $\begin{array}{l}\text { Directiva } \\
2008 / 50 / C E\end{array}$ & OMS \\
\hline $\mathrm{O}_{3}$ & Media máxima octohoraria & $120 \mu \mathrm{g} \cdot \mathrm{m}^{-3}$ & $100 \mu \mathrm{g} \cdot \mathrm{m}^{-3}$ \\
\hline $\mathrm{NO}_{2}$ & Media anual máxima & $40 \mu \mathrm{g} \cdot \mathrm{m}^{-3}$ & $40 \mu \mathrm{g} \cdot \mathrm{m}^{-3}$ \\
\hline $\mathrm{SO}_{2}$ & Media diaria máxima & $\begin{array}{l}125 \mu \mathrm{g} \cdot \mathrm{m}^{-3} \\
(>3 \mathrm{día} / \mathrm{año})\end{array}$ & $20 \mu \mathrm{g} \cdot \mathrm{m}^{-3}$ \\
\hline \multirow{2}{*}{$\mathrm{PM}_{10}$} & Media diaria máxima & $50 \mu \mathrm{g} \cdot \mathrm{m}^{-3}$ & $50 \mu \mathrm{g} \cdot \mathrm{m}^{-3}$ \\
\cline { 2 - 4 } & Media anual máxima & $40 \mu \mathrm{g} \cdot \mathrm{m}^{-3}$ & $20 \mu \mathrm{g} \cdot \mathrm{m}^{-3}$ \\
\hline
\end{tabular}

Las concentraciones de $\mathrm{NO}_{2}$, con una media anual de $37 \mu \mathrm{g} \cdot \mathrm{m}^{-3}$, no llegan a exceder los límites legales ni recomendados. Presenta un mínimo en primavera y verano, en concreto en el mes de abril, cuya concentración media es de $27 \mu \mathrm{g} \cdot \mathrm{m}^{-3}$, y un máximo en el periodo frío comprendido entre noviembre y febrero, siendo su concentración mensual máxima 
media de $49 \mu \mathrm{g} \cdot \mathrm{m}^{-3}$. Las altas concentraciones de $\mathrm{NO}_{2}$ registradas en otoño e invierno se asocian a su acumulación, debida a la menor altura de la capa de mezcla en combinación con la activación de las calefacciones (p. ej., Casquero-Vera et al., 2019; De Arruda Moreira et al., 2020), mientras que en verano se favorece la dispersión del mismo.

Por razones similares, la evolución diaria del $\mathrm{NO}_{2}$ (Figura 9) muestra dos máximos, en torno a las 11:00 y a las 22:00 h, coincidiendo aproximadamente con las horas punta de tráfico, mientras que durante la tarde las concentraciones disminuyen debido a la dispersión de contaminantes por un aumento de la altura de la capa de mezcla (Castillo et al., 2020). Como podemos observar también, existe una diferencia clara en la evolución diaria del $\mathrm{NO}_{2}$ si tenemos en cuenta los días laborables y el fin de semana. Puede verse (Figura 9) cómo de lunes a viernes los niveles de $\mathrm{NO}_{2}$ superan los del fin de semana, siendo el domingo el más bajo. Esto último también pone de manifiesto que la evolución semanal del $\mathrm{NO}_{2}$ está asociada con la evolución temporal del tráfico rodado.

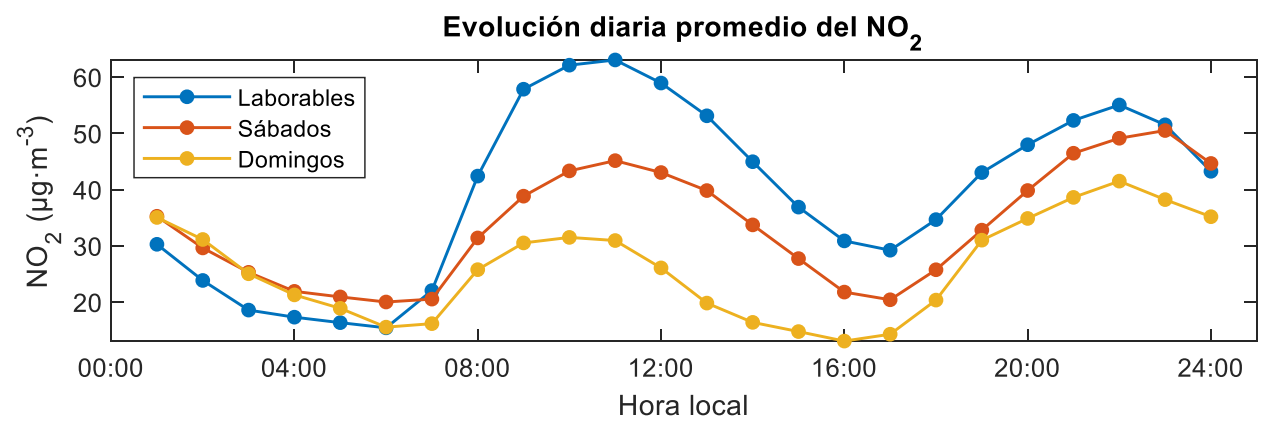

Figura 9. Evolución de promedios horarios de las concentraciones de $\mathrm{NO}_{2}$, según los días laborables, sábados y domingos.

La concentración de $\mathrm{O}_{3}$ muestra un claro patrón anual, como se esperaba, en el que aumenta la concentración en la época estival, debido a una mayor intensidad de la radiación solar, causante de las reacciones fotoquímicas que lo producen. Por el contrario, la concentración es menor en los meses invernales por la menor intensidad de la radiación y una mayor destrucción de ozono por titración. El comportamiento temporal del ozono es el contrario que el anteriormente comentado para $\mathrm{NO}_{2}$. El rango intercuartílico anual es de 31-80 $\mu \mathrm{g} \cdot \mathrm{m}^{-3}$, y la concentración anual media de $57 \mu \mathrm{g} \cdot \mathrm{m}^{-3}$. La mediana, $56 \mu \mathrm{g} \cdot \mathrm{m}^{-}$ 3 , prácticamente coincide con la media, lo que implica una distribución de valores simétrica, es decir, que no se producen muchos eventos extremos de ozono.

En la Figura 10 se puede observar el patrón de los promedios horarios del $\mathrm{O}_{3}$, teniendo en cuenta los días de la semana, que también muestra una relación con el patrón de $\mathrm{NO}_{2}$. En general, se produce un aumento de la concentración de $\mathrm{O}_{3}$ desde las 10:00 h, alcanzando un pico máximo entre las 16:00 y las 17:00 h (coincidiendo con el mínimo relativo de $\mathrm{NO}_{2}$ ), lo que está asociado con el aumento de la radiación solar. Cabe destacar que, como se muestra en el informe de la Evaluación de la Calidad del Aire en España (2017) y Ceballos et al. (2017), estas concentraciones llegan a ser altas, superándose en 25 y 110 ocasiones el límite establecido por la directiva Europea y el recomendado por la OMS. 


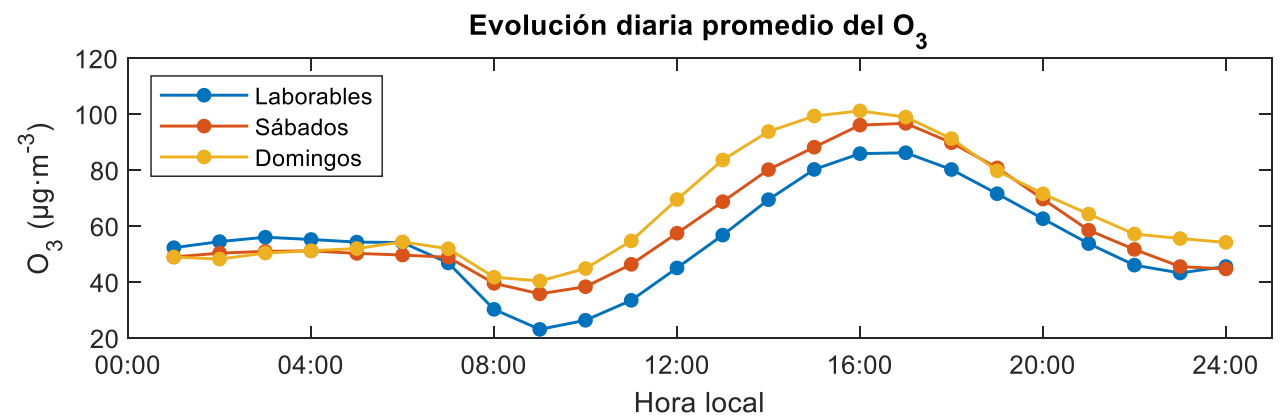

Figura 10. Evolución de los promedios horarios de las concentraciones de $\mathrm{O}_{3}$, según los días laborables, sábados y domingos.

En la Figura 11 mostramos la evolución de los promedios horarios de $\mathrm{NO}_{2}$ y $\mathrm{O}_{3}$ a lo largo de 2017. Se puede observar un acoplamiento entre ambas especies, lo cual podría estar relacionado estrechamente con el monóxido de nitrógeno, NO. Con el aumento matinal de los niveles de óxidos de nitrógeno asociados al tráfico rodado, el $\mathrm{O}_{3}$, al ser un compuesto altamente reactivo, se combina rápidamente con el $\mathrm{NO}$, conduciendo a un mínimo de ozono a las 09:00 h. A su vez, el $\mathrm{NO}$ se traduce en $\mathrm{NO}_{2}$ porque ambos gases también reaccionan muy rápidamente. A partir de las 17:00 h, la producción de ozono no compensa las pérdidas que se producen por su destrucción a causa de su reacción con el $\mathrm{NO}$, lo que genera que en las últimas horas del día se alcance un pico de $\mathrm{NO}_{2}$ y un mínimo de $\mathrm{O}_{3}$.

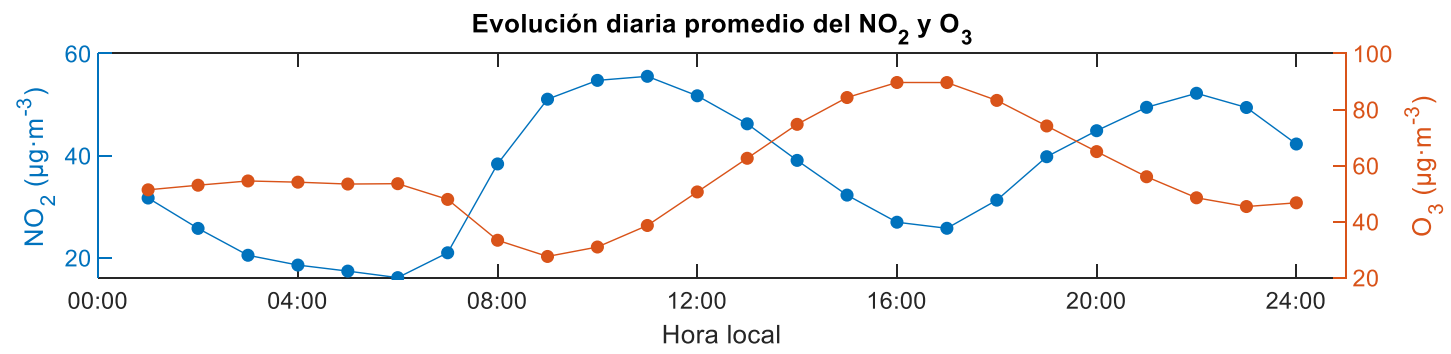

Figura 11. Evolución de promedios horarios de las concentraciones de $\mathrm{NO}_{2}$ (azul) y $\mathrm{O}_{3}$ (naranja).

Los promedios mensuales del dióxido de azufre $\left(\mathrm{SO}_{2}\right)$ no parecen tener una clara tendencia anual (Figura 8) y, además, las concentraciones de enero y diciembre son muy diferentes. En otros análisis realizados en años anteriores también se obtuvieron los mismos resultados (Casquero Vera et al., 2016). La concentración media mensual de $\mathrm{SO}_{2}$ varía entre 3 y $14 \mu \mathrm{g} \cdot \mathrm{m}^{-3}$, mientras que la concentración promedia del año 2017 es de 6 $\mu \mathrm{g} \cdot \mathrm{m}^{-3}$. Estas concentraciones son bajas si se comparan con los niveles de referencia recomendados por la OMS, y aún más con respecto al límite legal. Granada es una ciudad relativamente poco industrializada, lo que induce a niveles bajos este gas, el cual no está directamente relacionado con el tráfico.

En cuanto a la evolución diaria (Figura 12), aunque la representatividad de los promedios horarios durante las horas centrales del día no sea muy buena, debido a una considerable dispersión de los datos, sí que se puede destacar que hay un aumento de la concentración de $\mathrm{SO}_{2}$ desde las 08:00 hasta las 13:00 h, cuando se registra un máximo, para disminuir hasta las 00:00 h, hora a partir de la cual se mantiene la concentración mínima. También hay una diferencia entre los niveles de $\mathrm{SO}_{2}$ según el día de la semana, siendo los días laborables aquellos en los que mayores concentraciones se registran, seguidos de los sábados y los domingos. 


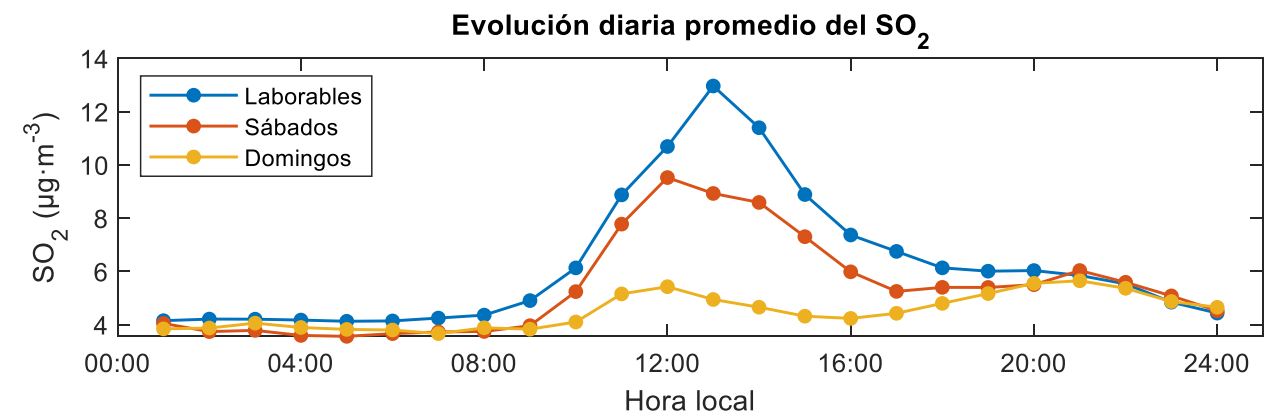

Figura 12. Evolución de los promedios horarios de las concentraciones de $\mathrm{SO}_{2}$, según los días laborables, sábados y domingos.

Los promedios mensuales de las concentraciones de $\mathrm{PM}_{10}$, (Figura 8), cuyo valor medio anual es del orden de $37 \mu \mathrm{g} \cdot \mathrm{m}^{-3}$ (mayor que el valor recomendado por la OMS y menor que el límite legal Europeo), muestran un pico máximo en los meses de verano, concretamente en agosto, con $52 \mu \mathrm{g} \cdot \mathrm{m}^{-3}$, mientras que disminuyen en los meses fríos, siendo su mínima mensual promedio de $23 \mu \mathrm{g} \cdot \mathrm{m}^{-3}$ en diciembre. Normalmente, aunque exista una importante variabilidad, las concentraciones más altas se dan en primavera y verano. Teniendo en cuenta algunos estudios previos (p. ej., Titos et al., 2014; Valenzuela et al., 2012a), esta variabilidad podría explicarse en parte por las intrusiones de polvo sahariano que suelen producirse en estas épocas del año, las escasas precipitaciones y la sequedad del terreno, lo cual facilita también la resuspensión de partículas. Además, este origen natural hace que predomine la fracción gruesa de partículas en el $\mathrm{PM}_{10}$ durante la época estival; en cambio, en invierno, debido al mayor peso de las partículas antropogénicas (tráfico y calefacciones domésticas) y a la menor altura de la capa límite, predomina la fracción fina de partículas en el $\mathrm{PM}_{10}$ (p. ej., Titos et al., 2012; Lyamani et al., 2010).

Los promedios anuales horarios de las concentraciones de $\mathrm{PM}_{10}$ (Figura 13) muestran dos máximos, a las 11:00-12:00 y a las 21:00 h, coincidiendo, al igual que en el caso del $\mathrm{NO}_{2}$, con los picos de mayor afluencia de tráfico. Durante la tarde se observa un mínimo relativo, posiblemente influenciado por la menor afluencia de tráfico rodado y por la dispersión de contaminantes producida a su vez por el aumento de la altura de la capa de mezcla (De Arruda Moreira et al., 2020). En este caso también pueden relacionarse los niveles de $\mathrm{PM}_{10}$ con el patrón de actividades antropogénicas, ya que se registran mayores concentraciones de partículas los días laborables que los sábados y domingos.

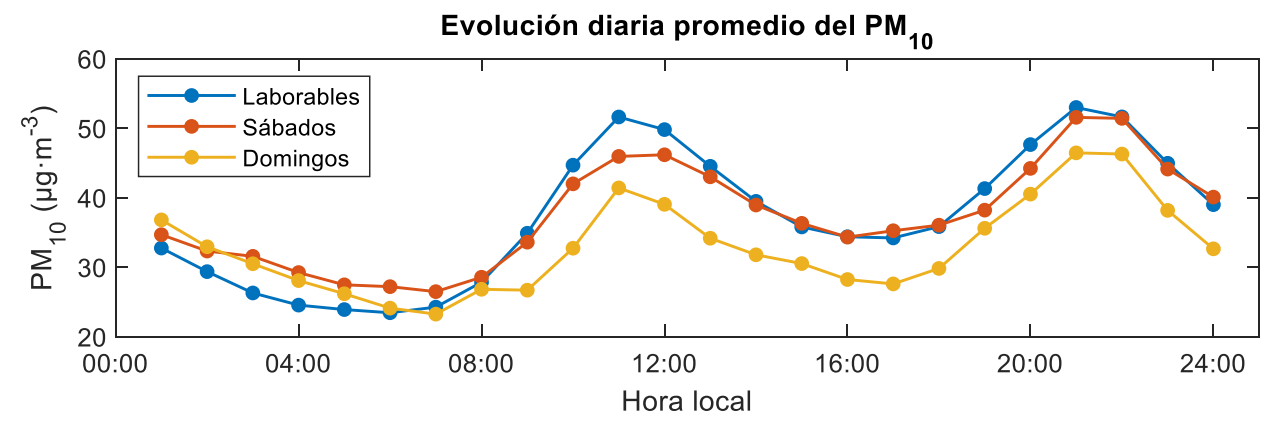

Figura 13. Evolución de promedios horarios de las concentraciones de $\mathrm{PM}_{10}$, según los días laborables, sábados y domingos.

En diferentes zonas urbanas europeas (Rodríguez and Cuevas, 2007), y en otras ciudades del mundo (Ruellan and Cachier, 2001; Latha and Badarinath, 2005; Baumgardner et al., 2007; Safai et al., 2007; Saha and Despiau, 2009; Dutkiewicz et al., 2009) se ha 
demostrado que los picos de BC (black carbon, hollín), observados durante la mañana y la tarde, están relacionados principalmente con las horas punta de tráfico rodado.

Este indicador de tráfico también se ha estudiado en la ciudad de Granada (p. ej., Lyamani et al., 2010; Lyamani et al., 2011), evidenciando que estas variaciones horarias se deben fundamentalmente a fuente locales, dominadas por el tráfico rodado.

Estos resultados coinciden también con otros análisis anteriores sobre la calidad del aire en Granada (p. ej., Casquero Vera et al., 2016; Secretaría de Medio Ambiente y Desarrollo Sustentable, 2012).

Finalmente, la evolución temporal de estos parámetros está relacionada con las condiciones meteorológicas y las tasas de emisión. En la estación fría, la menor altura de la capa límite planetaria, el predominio de la estabilidad atmosférica y una mayor actividad antropogénica en términos de tráfico rodado y calefacciones, favorece mayores concentraciones. En cambio, las concentraciones de ozono están moduladas principalmente por la radiación solar y su relación con los óxidos de nitrógeno, produciéndose un pico en primavera y verano.

\subsection{Partículas del aerosol atmosférico}

En la Figura 14 mostramos la evolución temporal de la concentración de partículas, según modos (nucleación, Aitken y acumulación), durante el año 2017.

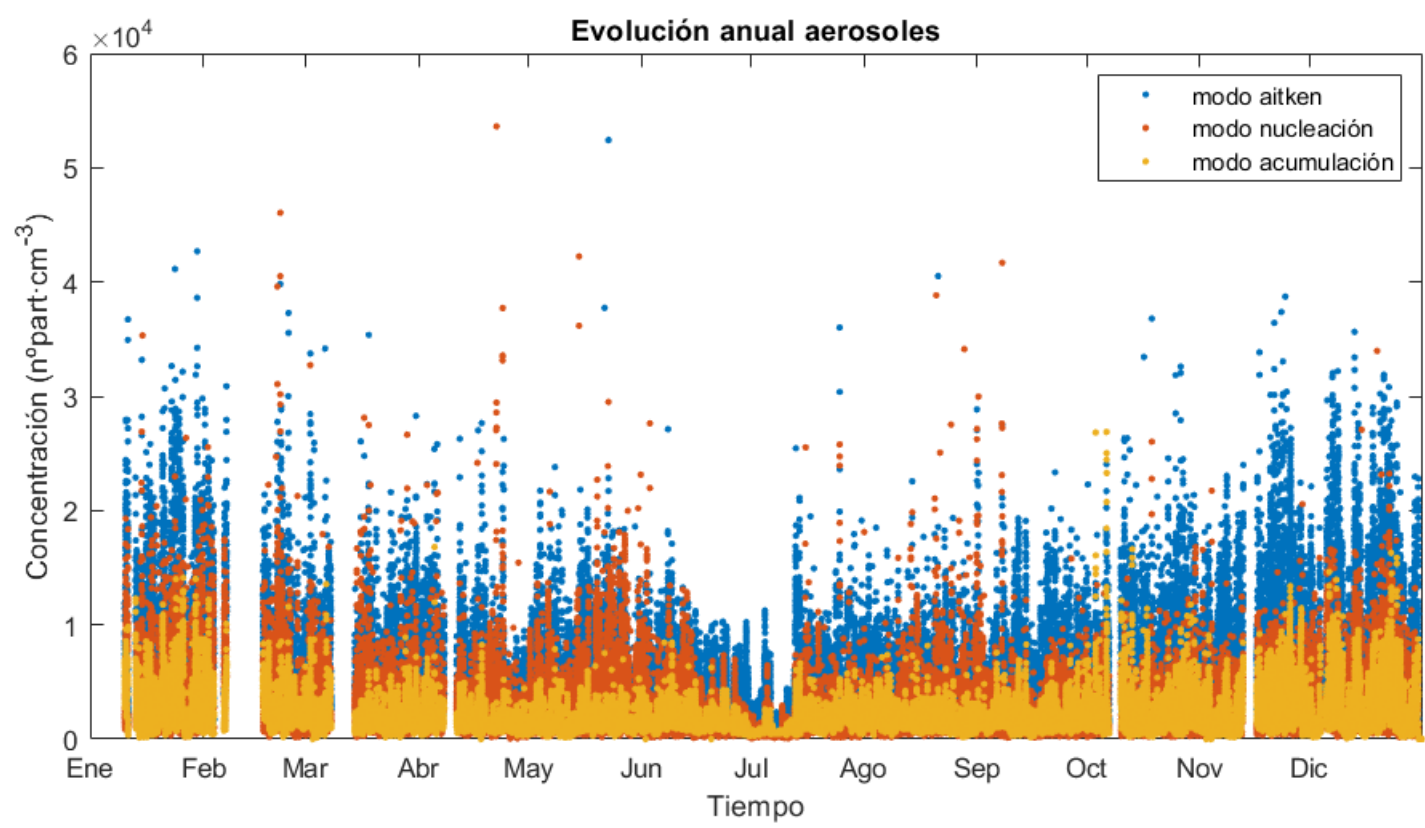

Figura 14. Evolución temporal de la concentración numérica de partículas, en $\mathrm{n}^{\mathrm{o}}$ part $\cdot \mathrm{cm}^{-3}$, durante el año 2017. Los puntos rojo, azul y naranja representan los modos de nucleación, Aitken y de acumulación respectivamente.

En la Figura 15 mostramos los promedios mensuales de las concentraciones para cada uno de los modos de partículas durante 2017. Podemos observar que las concentraciones de cada modo son más bajas en la época estival que en la época fría. Este resultado podría explicarse, como se comentaba anteriormente, por la gran contribución de emisiones antropogénicas en invierno, así como por las diferencias en las condiciones meteorológicas entre las distintas estaciones, principalmente por la variación de la capa límite planetaria, cuyo espesor aumenta en el período estival y en las horas centrales del 
día, produciendo así una disminución de la concentración de partículas en la época estival y un aumento en la época fría.

\section{Concentraciones mensuales de partículas}
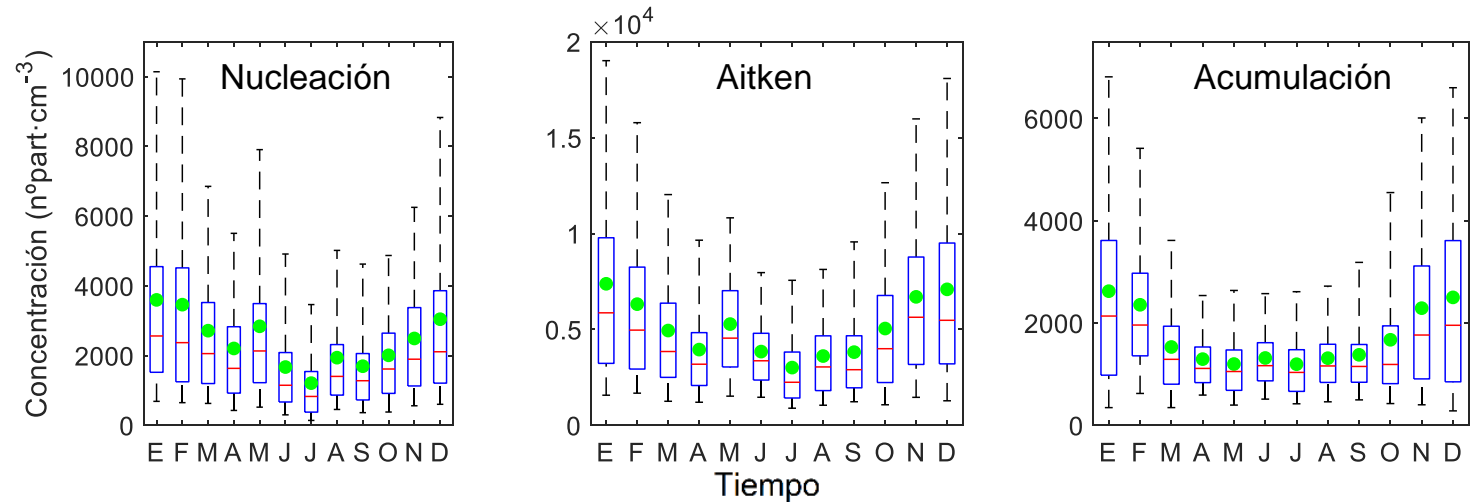

Figura 15. Evolución de la concentración numérica mensual de partículas, en $\mathrm{n}^{\mathrm{o}}$ part $\cdot \mathrm{cm}^{-3}$, durante el año 2017, para el modo de nucleación, Aitken y de acumulación, en las figuras de izquierda a derecha. Los límites de las cajas representan los percentiles 25 y 75; los de los diagramas, los percentiles 5 y 95; las líneas rojas se corresponden con las medianas; los puntos verdes, con las medias.

Como se podía intuir en la Figura 14, la contribución de cada modo (Figura 16) muestra que durante todo el año la concentración total está dominada por el modo Aitken, y las partículas de nucleación son ligeramente más predominantes que las del modo de acumulación. Es posible que la contribución del modo de nucleación sea más alta ya que no se han medido partículas menores de $12 \mathrm{~nm}$.
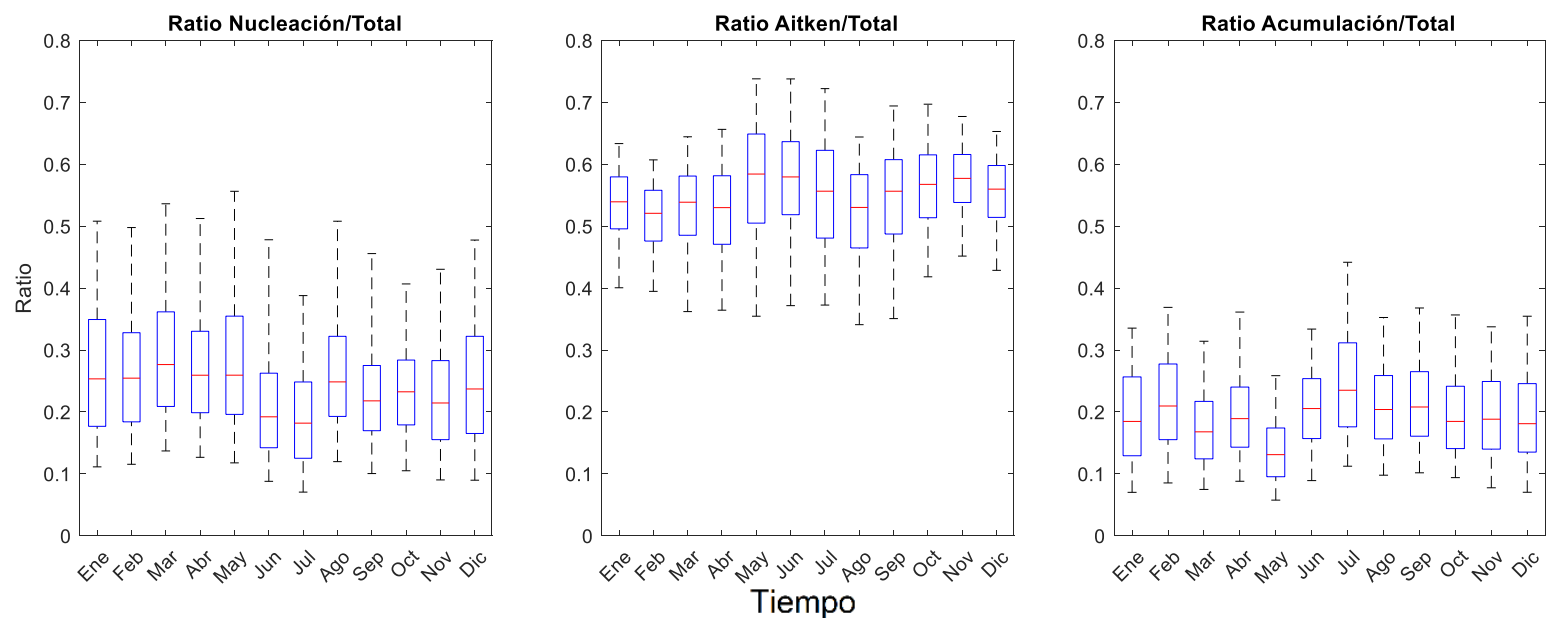

Figura 16. Ratio de la concentración mensual de cada modo de partículas entre el total, durante el año 2017, para el modo de nucleación, Aitken y de acumulación, en las figuras de izquierda a derecha. Los límites de las cajas representan los percentiles 25 y 75; los de los diagramas, los percentiles 5 y 95; las líneas rojas se corresponden con las medianas.

En la Tabla 2 mostramos un análisis estadístico del comportamiento medio de las concentraciones de partículas a nivel estacional y semanal durante 2017, distinguiendo cada modo en las estaciones fría (para el período comprendido entre octubre y marzo) y seca (entre abril y septiembre), y en los días laborales y del fin de semana. También se tienen en cuenta las partículas del rango completo de tamaños medidos (total) y el porcentaje de partículas del modo de nucleación con respecto al total, así como el de partículas ultrafinas (que incluye el modo de nucleación y aitken juntos) con respecto al total. 
Tabla 2. Media y desviación típica (SD) de la concentración de partículas $\left(10^{3} \cdot \mathrm{cm}^{-3}\right)$ de cada modo, del total y del porcentaje del modo de nucleación y partículas ultrafinas (nucleación y Aitken), para las estaciones fría y seca y para los días laborales (L), sábados (S) y domingos (D).

\begin{tabular}{|c|c|c|c|c|c|c|c|}
\hline \multirow{2}{*}{ Modo } & \multirow{2}{*}{ Parámetro } & \multicolumn{3}{|c|}{ Estación fría } & \multicolumn{3}{|c|}{ Estación seca } \\
\hline & & $\mathrm{L}$ & $S$ & $\mathrm{D}$ & $\mathrm{L}$ & $S$ & $\mathrm{D}$ \\
\hline \multirow{2}{*}{ Total } & Media & 11.6 & 11.0 & 9.1 & 7.4 & 6.8 & 5.9 \\
\hline & SD & 8.4 & 7.3 & 6.6 & 4.8 & 4.4 & 4.1 \\
\hline \multirow{2}{*}{ Nucleación } & Media & 2.9 & 2.7 & 2.3 & 2.0 & 1.8 & 1.7 \\
\hline & SD & 2.7 & 2.2 & 2.2 & 1.9 & 2.2 & 2.1 \\
\hline \multirow{2}{*}{ Aitken } & Media & 6.5 & 6.1 & 5.0 & 4.1 & 3.7 & 3.1 \\
\hline & SD & 5.0 & 4.3 & 3.8 & 2.9 & 2.4 & 2.2 \\
\hline \multirow{2}{*}{ Acumulación } & Media & 2.2 & 2.2 & 1.8 & 1.3 & 1.3 & 1.1 \\
\hline & SD & 1.8 & 1.9 & 1.6 & 0.8 & 0.7 & 0.5 \\
\hline \multirow{2}{*}{$\begin{array}{l}\text { Nucleación/Total } \\
(\%)\end{array}$} & Media & 26 & 26 & 25 & 25 & 24 & 25 \\
\hline & SD & 11 & 12 & 10 & 11 & 11 & 12 \\
\hline \multirow{2}{*}{ UFP/Total (\%) } & Media & 81 & 81 & 79 & 80 & 79 & 78 \\
\hline & SD & 8 & 9 & 9 & 9 & 10 & 9 \\
\hline
\end{tabular}

Como podemos observar en la Tabla 2, en la estación fría las concentraciones del total de partículas son mayores que en la estación seca, coincidiendo con lo anteriormente observado en la Figura 14 y Figura 15. Este resultado se debe, como se ha comentado anteriormente, a la menor altura de la capa de mezcla en la estación fría (De Arruda Moreira et al., 2020), al predominio de las condiciones de estabilidad atmosférica y, como consecuencia, a una menor dispersión de los gases y partículas, sumado a la puesta en marcha de las calefacciones domésticas y las quemas de biomasa durante la estación fría.

Además, en los días laborables de ambos períodos frío y seco se registran también mayores concentraciones de partículas, seguidas de los sábados, siendo los domingos los días con menos concentración de partículas. Este hecho está asociado al patrón semanal de tráfico rodado en la ciudad de Granada.

Los porcentajes de las concentraciones de nucleación son del 24 al 26\%, siendo mínimas las diferencias entre la estación fría y seca. Esto también se observa en la Figura 17, lo que parece indicar que en el período seco la NPF compensa en parte la disminución de concentraciones de partículas que se produce.

Por otro lado, el porcentaje de las concentraciones UFPs, es decir, del modo de nucleación y de Aitken juntos, varía entre 78 y $81 \%$, lo cual es similar a los resultados encontrados en estudios previos (p. ej., Rodríguez et al., 2007; Salma et al., 2011), que muestran unos porcentajes característicos de estaciones de fondo de zonas urbanas y expuestas al tráfico, de entre 70 y $90 \%$.

Como podemos observar también en la Tabla 2, las concentraciones del modo Aitken son las que predominan, independientemente del día de la semana y de la estación del año, seguido del modo de nucleación y, por último, el modo de acumulación. 
En la Figura 17 se muestra la distribución media de tamaños de partículas media a lo largo de 2017, distinguiendo la estación fría y la seca. En ella se observa también el aumento de la concentración en número de partículas, en todos los rangos de tamaño, en la estación fría. Hay que destacar que las diferencias son menores en los tamaños de partículas más pequeños, del orden de los $12 \mathrm{~nm}$, así como en los de $500 \mathrm{~nm}$. En concreto, para el modo de nucleación, este resultado podría mostrar que, durante la estación seca, pese a la dispersión de partículas, la NPF es una importante fuente que compensa la reducción de la concentración de partículas por dicha dispersión.

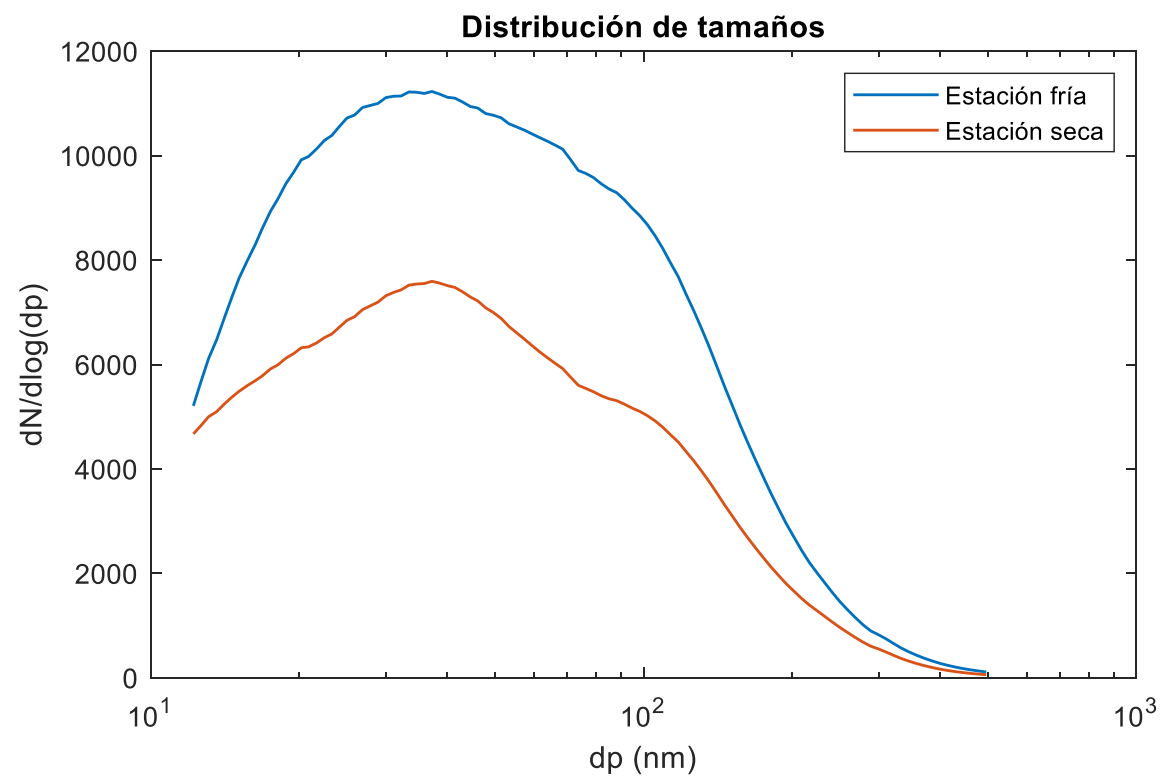

Figura 17. Distribución de tamaño de partículas promedia $\left(n^{\circ}\right.$ part $\left.\cdot \mathrm{cm}^{-3}\right)$, según las estaciones fría y seca, en el rango de tamaños de 12 a $500 \mathrm{~nm}$.

La Figura 18 muestra la evolución diaria media de las concentraciones de partículas según las diferentes estaciones del año y modos. Como se mencionaba anteriormente, se observa el predominio del modo Aitken, independientemente del momento del año y de la hora del día. Las concentraciones medias presentan dos picos que podemos asociar a las horas punta de tráfico (a las 8:00 y 20:00 h), destacando principalmente los modos de nucleación y Aitken. Este resultado evidencia nuevamente el papel del tráfico rodado en la evolución temporal diaria de las concentraciones de partículas, similar a los resultados de la revisión de Morawska et al. (2008), donde sintetizaron el conocimiento científico sobre las UFPs procedentes de emisiones de vehículos. En este caso, el origen de las UFPs es el enfriamiento y condensación de los gases expulsados por los tubos de escape para formar partículas, sin que intervenga la radiación solar.

Destacaremos también en la Figura 18 el tercer pico que aparece en las concentraciones medias diarias del modo de nucleación en los meses de primavera y verano (estación seca), que tiene lugar durante el mediodía. Este hecho queda explicado por la formación y crecimiento de nuevas partículas, NPF. 

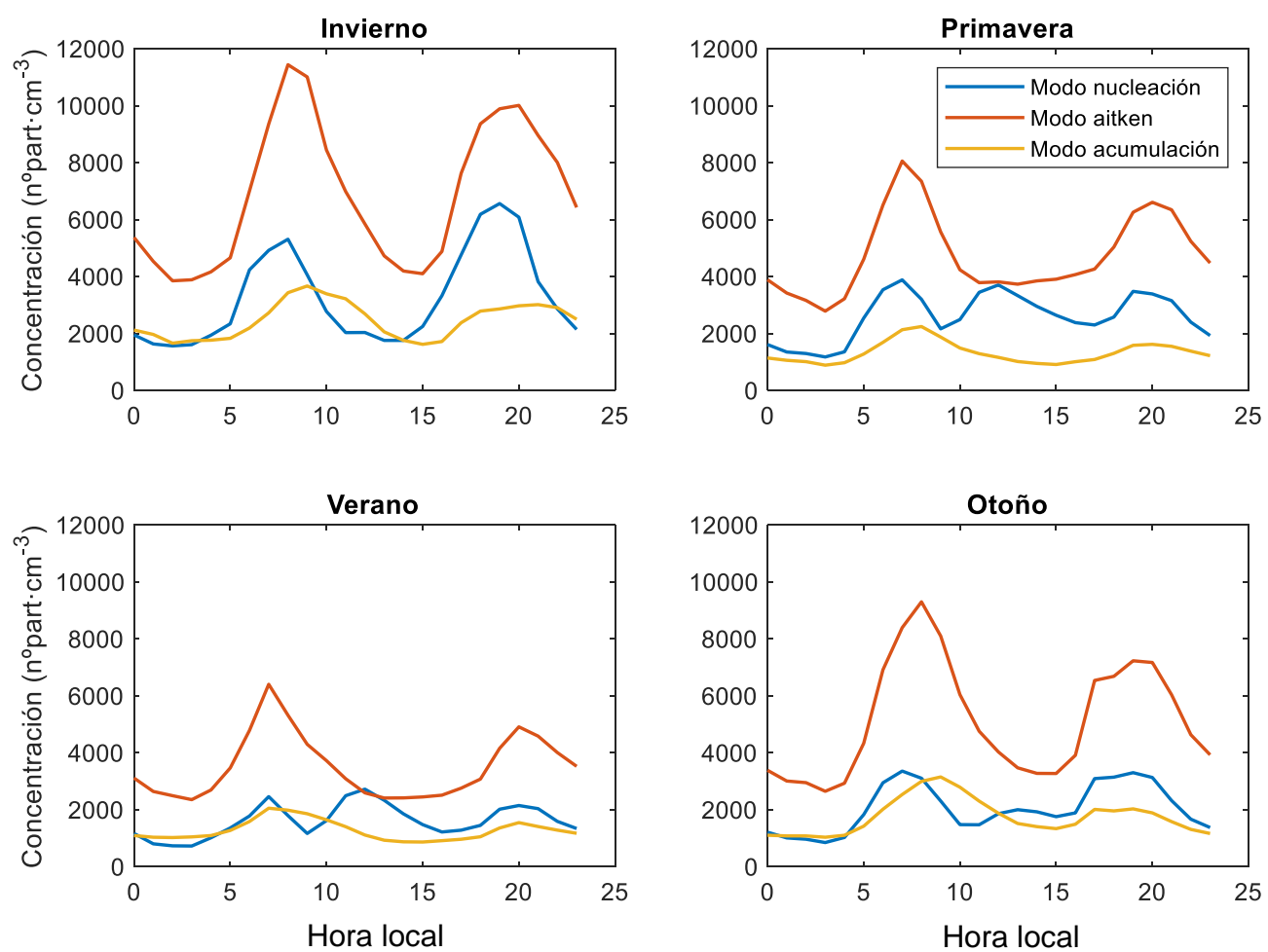

Figura 18. Evolución diaria de las concentraciones medias de partículas por estaciones, en $\mathrm{n}^{\mathrm{o}}$ part $\cdot \mathrm{cm}^{-3}$, según los modos de distribución: línea azul para el modo de nucleación, naranja para el modo Aitken y amarillo para el modo de acumulación.

\subsection{Caracterización inicial de los eventos de NPF}

En la Tabla 3 mostramos la clasificación del número de eventos de formación de nuevas partículas (NPF) identificados durante el año 2017. La Figura 19 muestra el porcentaje que representa cada uno de los eventos sobre el total de los mismos.

Tabla 3. Resultados de la clasificación de eventos.

\begin{tabular}{|l|l|l|}
\hline \multirow{2}{*}{ Evento } & Clase I & 43 \\
\cline { 2 - 3 } & Clase II & 85 \\
\hline No evento & 128 \\
\hline Indefinido & 51 \\
\hline Sin datos & 58 \\
\hline
\end{tabular}




\section{Contribución de los tipos de eventos}

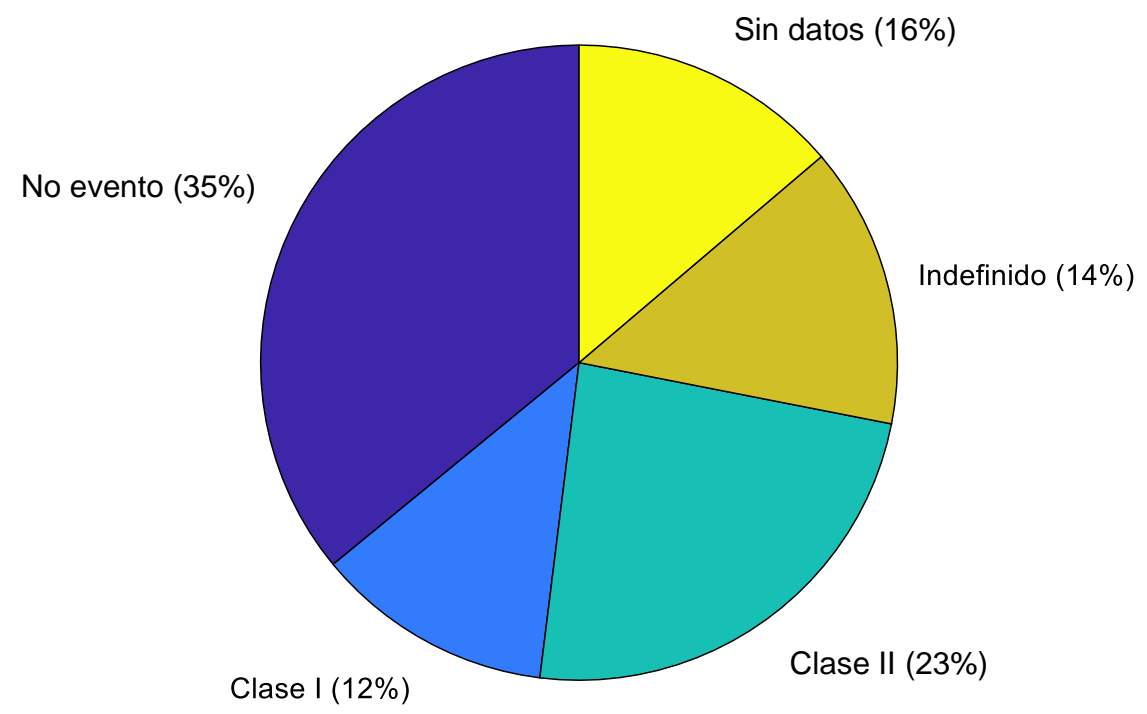

Figura 19. Porcentaje de cada uno de los eventos respecto al total.

En el 35\% de los días analizados (128 días) no se produjo formación de nuevas partículas. El resultado es el mismo para los días en los que sí se dio NPF, un 35\% si se suman los eventos de Clase I (12\%) y Clase II (23\%). Hay una menor proporción de días que se clasificaron como indefinidos (14\%) y sin datos (16\%).

En la Figura 20 mostramos la evolución anual de los días con eventos, según la clasificación, durante 2017. Se observa que los de Clase I se producen exclusivamente en los meses de junio, julio, agosto y septiembre, mientras que la Clase II se puede producir a lo largo de todo el año. Por otro lado, aunque haya días sin eventos en el período estival, éstos tienen una mayor ocurrencia en otoño e invierno. Acorde a nuestros resultados, muchos estudios también han demostrado que los eventos NPF se producen con una mayor frecuencia en verano que en inverno (p. ej., Qian et al 2007, Dall'Osto et al 2018, Nieminen et al 2018).

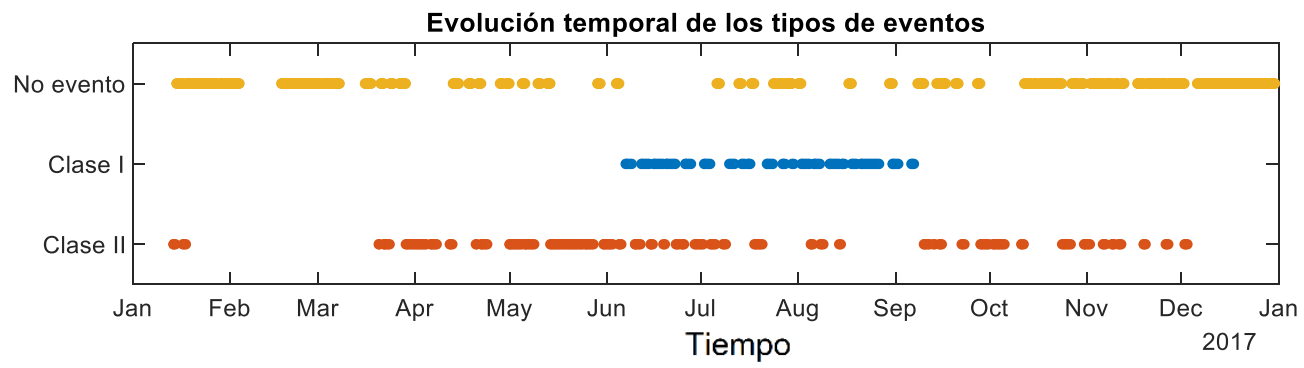

Figura 20. Evolución anual de los días con eventos, clasificados como No evento (amarillo), Clase I (azul) y Clase II (rojo).

La Figura 21 muestra la clasificación de eventos, en porcentaje, para los meses de junio a septiembre. En estos meses se producen eventos en la mayor parte de los días: $35 \%$ de Clase I y $24 \%$ de Clase II. En total, durante estos meses, en el 59\% de los días se produjeron eventos de NPF. En solo un 14\% de los días no se manifestó la formación y crecimiento de partículas, aunque un $26 \%$ se clasificó como día indefinido, y hubo sólo un $1 \%$ de días sin datos. 


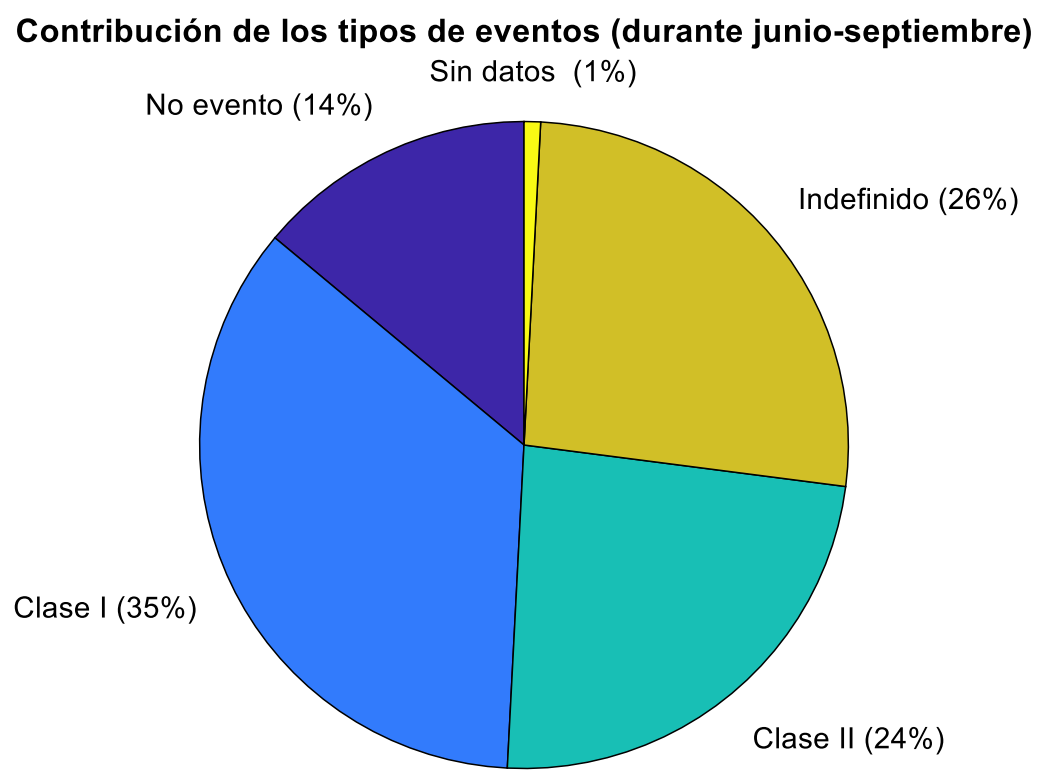

Figura 21. Distribución en porcentaje de los tipos de eventos respecto al total de casos, entre junio y septiembre.

En la Figura 22 mostramos la evolución temporal de la concentración de partículas del modo de nucleación (junio-septiembre), promediada diariamente en el rango horario de 10:00 h a 15:00 h (período en el que se produce la formación), junto al valor de la tasa de formación (FR). Esta serie temporal incluye también los días en los que no se produjeron eventos de NPF, lo que hace que no coincida el número de casos representados. Aun así, se observa en la Figura 22 una posible correlación entre ambas variables. Además, también se observa que la mayoría de los picos de formación vienen acompañados por aumentos de la concentración de partículas del modo de nucleación. En la Figura 23 mostramos los valores de la concentración de partículas del modo de nucleación frente a la tasa de formación, donde se observa que el aumento de la tasa de formación explica en parte el aumento de la concentración de partículas de este modo.

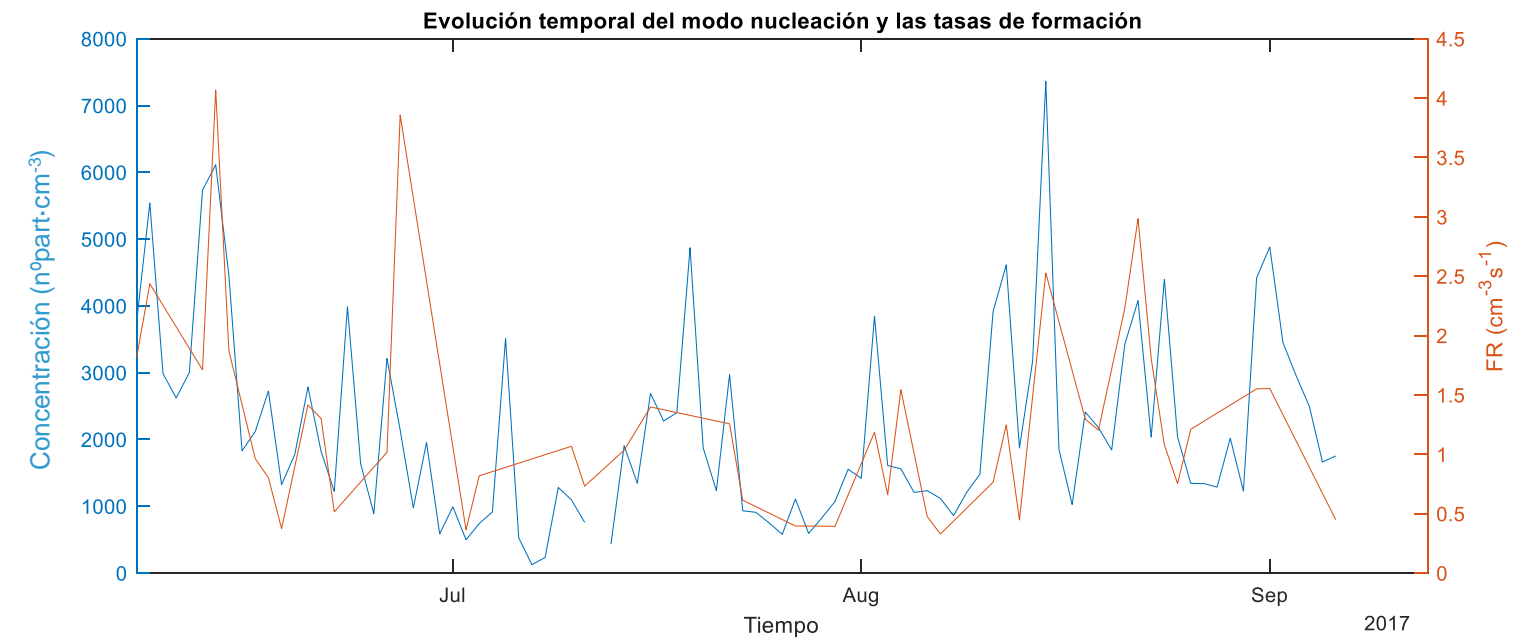

Figura 22. Evolución temporal de la concentración de partículas del modo de nucleación $\left(\mathrm{n}^{\mathrm{o}} \mathrm{part} \cdot \mathrm{cm}^{-3}\right)$ y la tasa de formación (en $\mathrm{cm}^{-3} \mathrm{~s}^{-1}$ ) en los meses de junio a septiembre de 2017. 


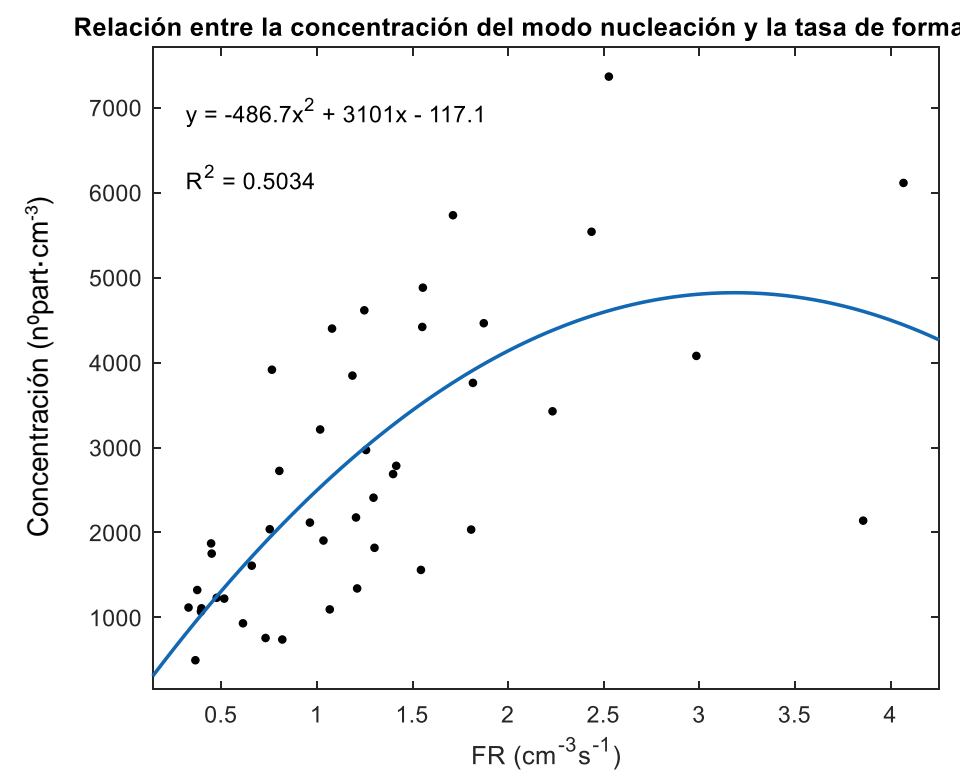

Figura 23. Valores de la concentración de partículas del modo de nucleación $\left(\mathrm{n}^{\mathrm{o}}\right.$ part $\left.\cdot \mathrm{cm}^{-3}\right)$ frente a la tasa de formación $\left(\mathrm{cm}^{-3} \cdot \mathrm{s}^{-1}\right)$ para los eventos de los meses de junio a septiembre de 2017.

En la Figura 24 podemos observar la evolución temporal de las tasas de formación (FR) y crecimiento (GR) para los eventos de los meses de junio a septiembre de 2017. Esta figura muestra que no hay una correlación entre ambos procesos debido a que están controlados por distintos factores.

La FR media registrada es de $1.2 \mathrm{~cm}^{-3} \cdot \mathrm{s}^{-1}$, el valor mínimo es de $0.3 \mathrm{~cm}^{-3} \cdot \mathrm{s}^{-1}$, y el valor máximo $4.0 \mathrm{~cm}^{-3} \cdot \mathrm{s}^{-1}$. Esta FR media es inferior a la tasa de formación media para zonas urbanas, de $2.9 \mathrm{~cm}^{-3} \cdot \mathrm{s}^{-1}$, obtenida por Kerminen et al. (2018). La GR varía entre 2.2 y 9.0 $\mathrm{nm} \cdot \mathrm{h}^{-1}$, siendo su valor medio de $4.1 \mathrm{~nm} \cdot \mathrm{h}^{-1}$. Otros autores han mostrado que la tasa de crecimiento media para zonas urbanas es de $5.9 \mathrm{~nm} \cdot \mathrm{h}^{-1}$ (Kerminen et al., 2018), y puede llegar a superar los $10 \mathrm{~nm} \cdot \mathrm{h}^{-1}$ en zonas muy contaminadas (p. ej., Wu et al., 2007).

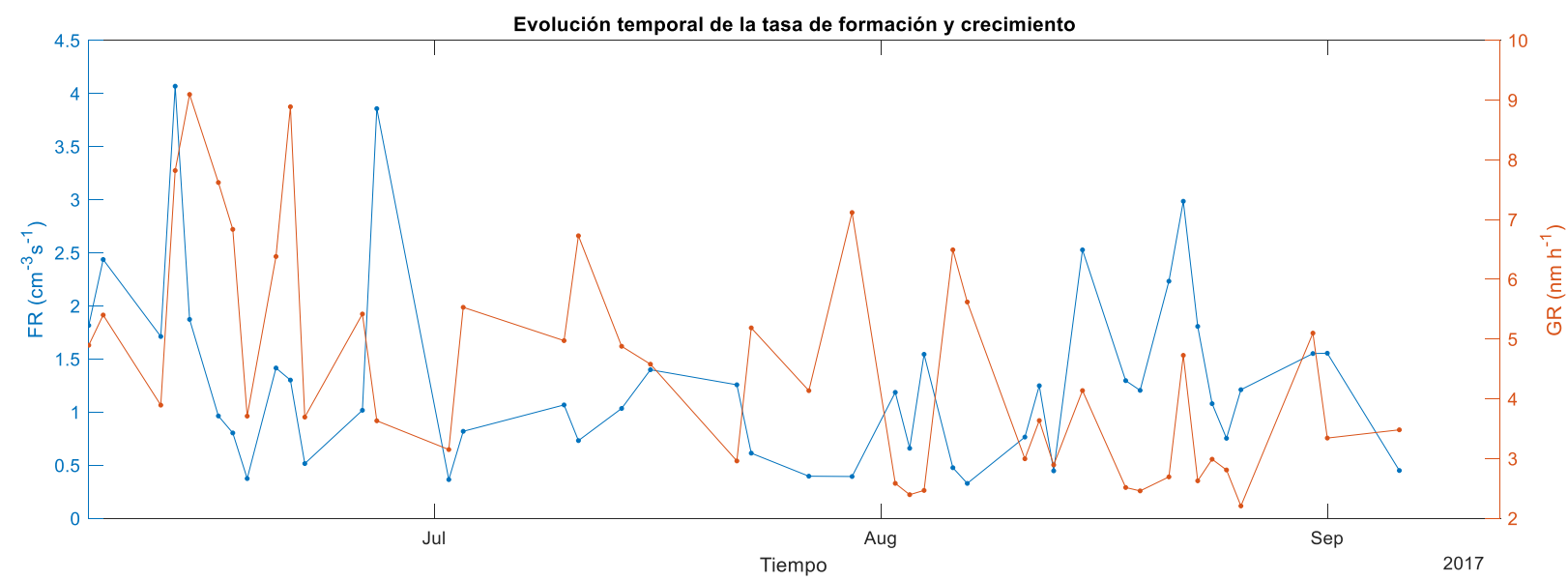

Figura 24. Evolución temporal de la tasa de formación $\left(\mathrm{cm}^{-3} \cdot \mathrm{s}^{-1}\right)$ y la tasa de crecimiento $\left(\mathrm{nm} \cdot \mathrm{h}^{-1}\right)$ para los eventos de los meses de junio a septiembre de 2017 .

\subsection{Relación de los eventos de NPF con otros parámetros}

En la Figura 25 se puede observar la evolución diaria de las concentraciones promedio horarias de partículas, de junio a septiembre de 2017, para los modos de nucleación, 
Aitken y acumulación, así como el total (12-500 nm), de los días clasificados como Clase I (en adelante mencionados como Evento NPF) y No evento. Como podemos ver, las concentraciones promedio de los distintos modos presentan dos picos, relacionados con el tráfico rodado (08:00 y 21:00 h), presentando además el modo de nucleación otro pico en el día de Evento NPF, producido por la formación de nuevas partículas, lo cual también se pone de manifiesto en la gráfica correspondiente a la suma de los modos (Total). Destacaremos también que, a diferencia del comportamiento de las partículas del modo de acumulación, en el que las concentraciones del día No evento (línea naranja) son mayores en todos los casos a las concentraciones del día Evento NPF (línea azul), el modo de Aitken muestra concentraciones superiores en el día Evento NPF, desde las 12:00 h, con respecto al día No evento. Es posible que este hecho ponga de manifiesto que las partículas recién formadas (modo de nucleación) crezcan hasta llegar al siguiente rango de tamaños, correspondiente al modo de Aitken. Este resultado muestra la posible importancia de la contribución de los episodios de NPF como fuente de partículas, puesto que llegan a dominar en número la fracción fina de partículas: el total de estas partículas en los días Eventos NPF llega a superar en concentración, desde el mediodía, al total registrado para días No evento.
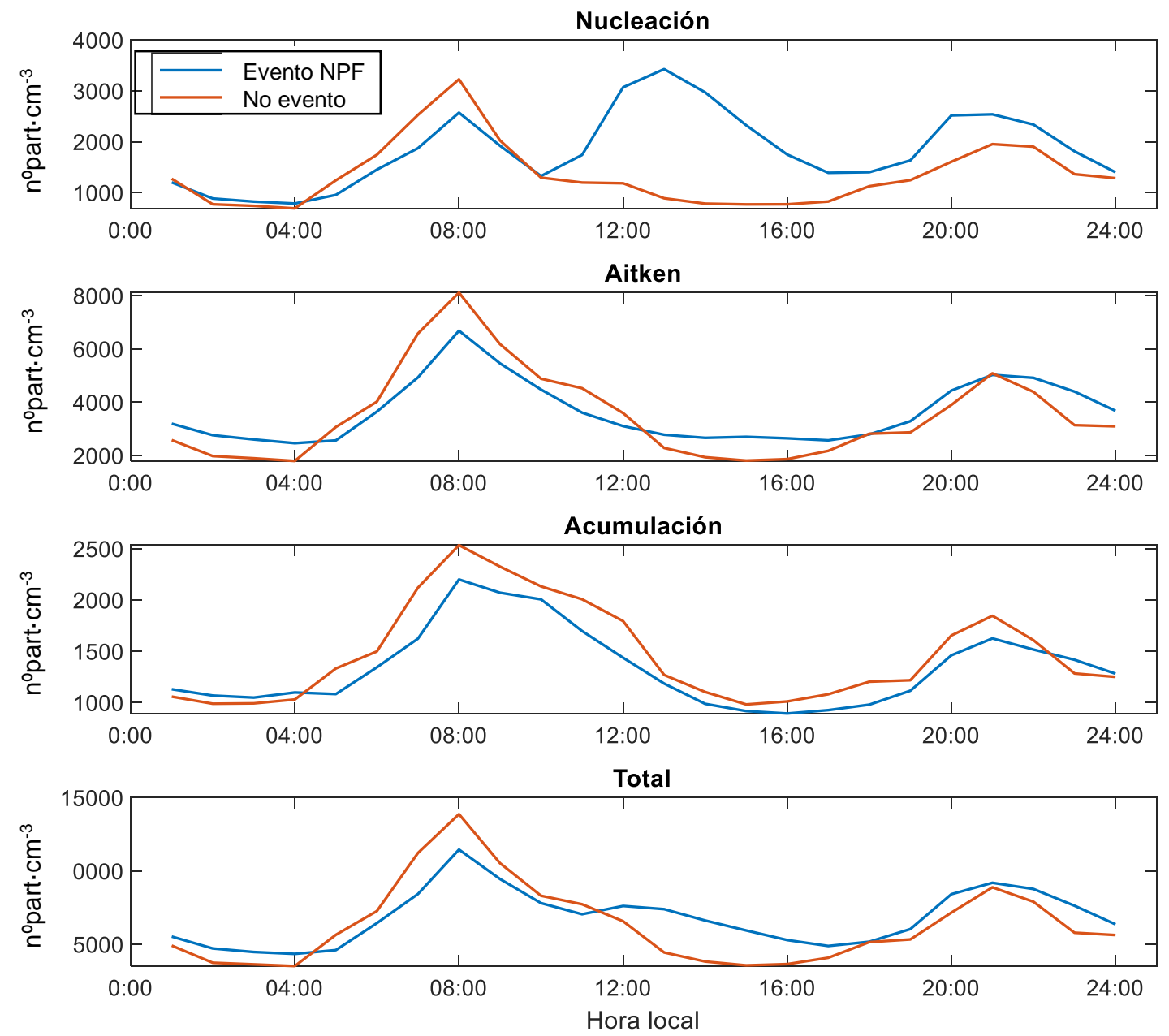

Figura 25. Evolución diaria de la concentración media horaria de partículas de los modos de nucleación, Aitken, acumulación y total, en $\mathrm{n}^{\mathrm{o}}$ part $\cdot \mathrm{cm}^{-3}$, para los días con Evento NPF y No evento en los meses de junio a septiembre de 2017.

La Figura 26 muestra la evolución horaria de los promedios de $\mathrm{PM}_{10}$ para días clasificados como Evento NPF y para No evento. Como podemos observar, los días No evento se 
caracterizan por tener una mayor concentración de partículas, lo que podría indicar que el nivel de partículas sea un factor condicionante para que se dé o no la NPF.

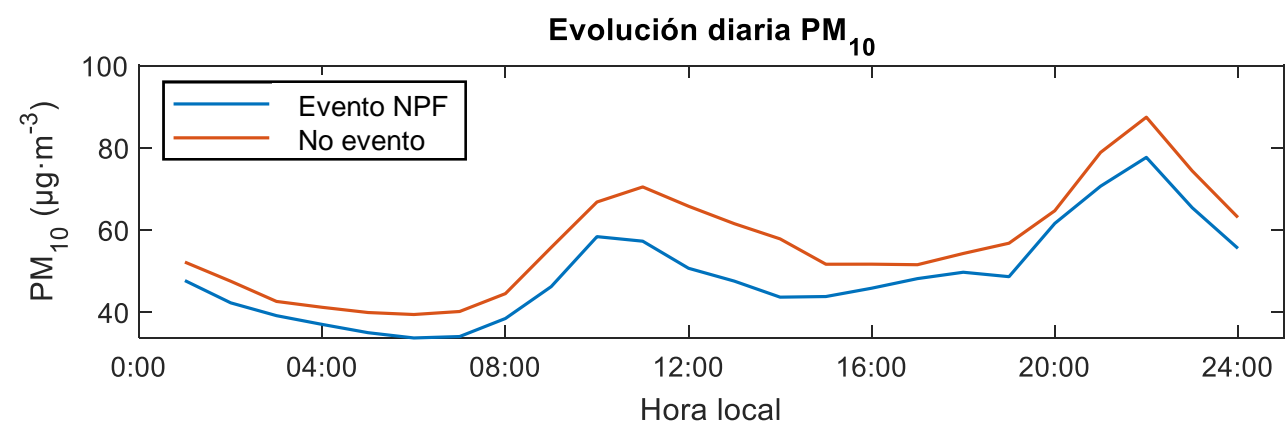

Figura 26. Evolución de la concentración media horaria de $\mathrm{PM}_{10}$ para días Evento NPF y No evento, en los meses de junio a septiembre de 2017.

Teniendo en cuenta estos resultados, hemos analizado también el parámetro sumidero de condensación (CS). El valor promedio de CS obtenido para el período de producción de nuevas partículas, junio-septiembre de 2017, considerando el tramo horario de 6:00 a 10:00 h (período previo a la formación de partículas, que posiblemente la condicione), es mayor para días clasificados como No evento, con un valor de 0.0135 , y menor para los días con Evento, 0.0113 y 0.0103 para la Clase I y la Clase II, respectivamente. Los días Indefinidos mantienen un valor intermedio de 0.0112 (Tabla 4). Estos resultados parecen indicar lo esperado, que una mayor presencia de partículas preexistentes dificulta la formación de nuevas partículas. No obstante, comparando los días con Evento de Clase I y Clase II, el sumidero de condensación es mayor en los días en los que los eventos de NPF son más evidentes.

Algunos estudios previos obtienen también estos resultados, como Dal Maso et al. (2007), Birmili et al. (2003), Salma et al. (2016) y Dada et al. (2017). Aunque otros como Kulmala et al. (2017) también han observado la ocurrencia de NPF con altos valores de CS.

Tabla 4. Valor promedio del sumidero de condensación (CS) calculado para los días clasificados como Evento (Clase I y Clase II), Indefinido y No evento, en los meses de junio a septiembre de 2017.

\section{CS promedio}

\begin{tabular}{|l|c|c|}
\hline \multirow{2}{*}{ Evento } & Clase I & 0.0113 \\
\hline & Clase II & 0.0103 \\
\hline Indefinidos & 0.0112 \\
\hline \multicolumn{2}{|c|}{ No eventos } & 0.0135 \\
\hline
\end{tabular}

En la Figura 27 mostramos la evolución diaria promedio de los parámetros de calidad del aire y de las partículas del modo de nucleación $(<25 \mathrm{~nm})$ para los días Evento NPF y los días No evento. Se observa nuevamente en estas gráficas que el comportamiento de partículas y gases está asociado con la actividad antropogénica y, como consecuencia, se observan los picos característicos asociados al tráfico rodado. Las concentraciones promedio de $\mathrm{NO}_{2}$ son mayores en los días de No evento que en los días de Evento NPF, mientras que las concentraciones promedio de $\mathrm{O}_{3}$ son mayores en los días de Evento NPF. Teniendo en cuenta estos resultados, podríamos asociar el aumento de partículas de nucleación con el aumento de ozono, destacando así su relación positiva con la formación 
de nuevas partículas. El $\mathrm{PM}_{10}$ presenta concentraciones promedio mayores en los días de No evento, ya que posiblemente su mayor presencia dificulta la formación de nuevas partículas. Cabe destacar en la Figura 27 la correlación entre el pico en las concentraciones promedio de $\mathrm{SO}_{2}$ y las concentraciones de partículas del modo de nucleación para los días de Evento NPF, que evidencia su papel como gas precursor. Por otro lado, las concentraciones promedio de $\mathrm{SO}_{2}$ son prácticamente similares para ambos días, lo que podría indicar que su nivel no determina en este caso la ocurrencia de la NPF. Estos resultados podrían mostrar que el ozono y el dióxido de azufre tienen un papel en la formación de nuevas partículas, aunque también otras variables pueden condicionar estos eventos, como puede ser la concentración de partículas preexistentes.

Otros estudios previos también analizaron las variables que podrían favorecer los episodios de $\mathrm{NPF}$, como el $\mathrm{O}_{3}$ y $\mathrm{SO}_{2}$, y las variables que podrían dificultarlos, como las partículas preexistentes, las cuales podrían ser incluyo las propias partículas del modo de nucleación si se produjo un evento el día previo.

Carnero et al. (2018) y Querol et al. (2018) han estudiado también la relación entre $\mathrm{O}_{3}$ y NPF. Sus resultados muestran que, aunque la concentración de $\mathrm{O}_{3}$ fue alta durante el periodo analizado (julio de 2016 en Madrid), la formación de nuevas partículas solo ocurría con bajos niveles de $\mathrm{O}_{3}$. Por el contrario, picos de concentraciones máximas de $\mathrm{O}_{3}$ se correspondían con la no ocurrencia de NPF. Carnero et al. (2019) llevaron a cabo otro estudio similar en Barcelona, analizando la primavera y el verano entre 2014 y 2018, concluyendo que las concentraciones más altas de $\mathrm{O}_{3}$ coincidieron con los mayores picos de UFPs, pero la NPF se inhibía probablemente por la elevada concentración de partículas. De manera contraria, los episodios de NPF tuvieron lugar con bajos niveles de $\mathrm{O}_{3}$ y UFPs. Sin embargo, otros trabajos como los llevados a cabo por Fernández-Camacho et al. (2010) en Huelva, que cubrían un año completo de estudio, mostraron una coincidencia entre los picos de concentraciones máximas de $\mathrm{O}_{3}$ y la ocurrencia de NPF, siendo sus resultados similares a los de este trabajo. Es interesante que este último estudio también estimó que el $80 \%$ de las nuevas partículas estaban relacionadas con las emisiones de $\mathrm{SO}_{2}$. También otro estudio sobre un área rural en China (Wang et al., 2016) durante 2013 llegó a la conclusión de que la NPF ocurría cuando se registraban las mayores concentraciones de $\mathrm{O}_{3}$. Desde el punto de vista del papel del $\mathrm{SO}_{2}$ en la ocurrencia de eventos de NPF, en general, las observaciones no son concluyentes. Algunos estudios (p. ej., Birmili and Wiedensohler, 2000; Boy et al., 2008) han comprobado que durante los episodios de NPF las concentraciones de $\mathrm{SO}_{2}$ eran altas comparadas con los días sin NPF y, sin embargo, otros (p. ej., Wu et al., 2007) han observado lo contrario, que las concentraciones de este gas son menores en los días con NPF que sin ellos. 

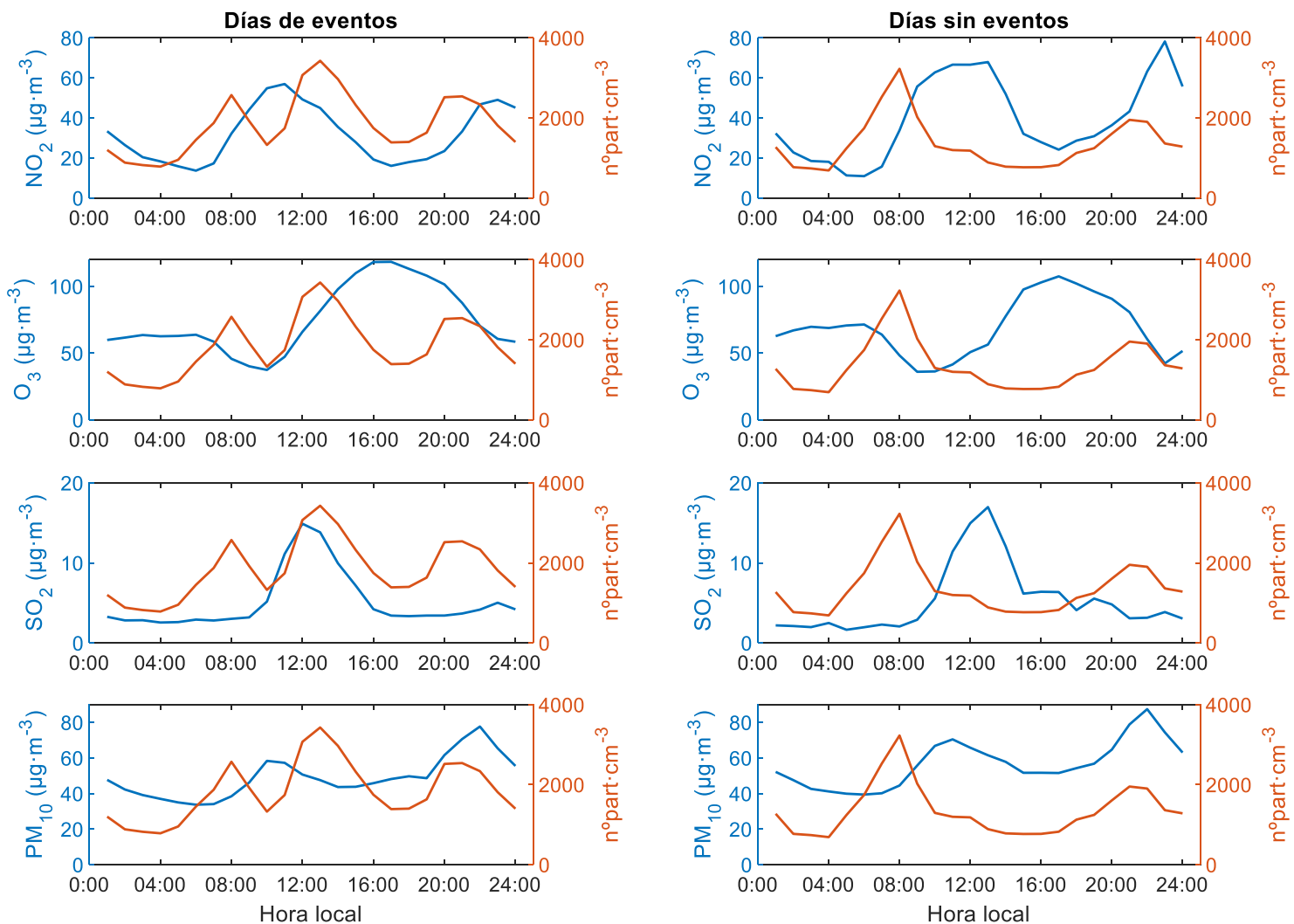

Figura 27. Evolución diaria de la concentración promedio de partículas del modo de nucleación y los parámetros de calidad del aire en los meses de junio a septiembre de 2017. En la columna izquierda, los días de Evento NPF; en la derecha, días No evento.

\subsubsection{Estudio de las tasas de formación de partículas}

Analizaremos en los siguientes párrafos las condiciones o parámetros que intervienen en el grado de formación de nuevas partículas durante el periodo de medidas de junio a septiembre de 2017. Para ello compararemos las tasas de formación de partículas con los parámetros de calidad del aire y los valores de CS.

En la Figura 28 (izquierda) podemos observar una correlación positiva entre las concentraciones promedio del dióxido de azufre y la tasa de formación (FR). La variabilidad queda explicada en un $44 \%$ para las concentraciones promedio de $\mathrm{SO}_{2}$, con un nivel de confianza del $95 \%$. En este sentido, podríamos afirmar que a mayor concentración de $\mathrm{SO}_{2}$ mayor es la tasa de formación de nuevas partículas, lo que pone de manifiesto el papel de este gas como gas precursor de la formación de partículas. La Figura 28 (derecha) también muestra la relación entre las concentraciones promedio de $\mathrm{SO}_{2}$, los promedios de la tasa de formación (FR) y los valores promedio para el sumidero de condensación (CS), mostrando una tendencia positiva entre estas variables. La relación parece mostrar que coinciden bajos niveles de CS con bajas concentraciones de $\mathrm{SO}_{2}$, quizá debido a la dependencia de ambas variables con las condiciones atmosféricas. En la Figura 28 (inferior) se han agrupado los valores según la concentración promedio de ozono. Los resultados podrían mostrar que, para una misma concentración de $\mathrm{SO}_{2}$, menos concentración de $\mathrm{O}_{3}$ podría favorecer la formación de nuevas partículas. 

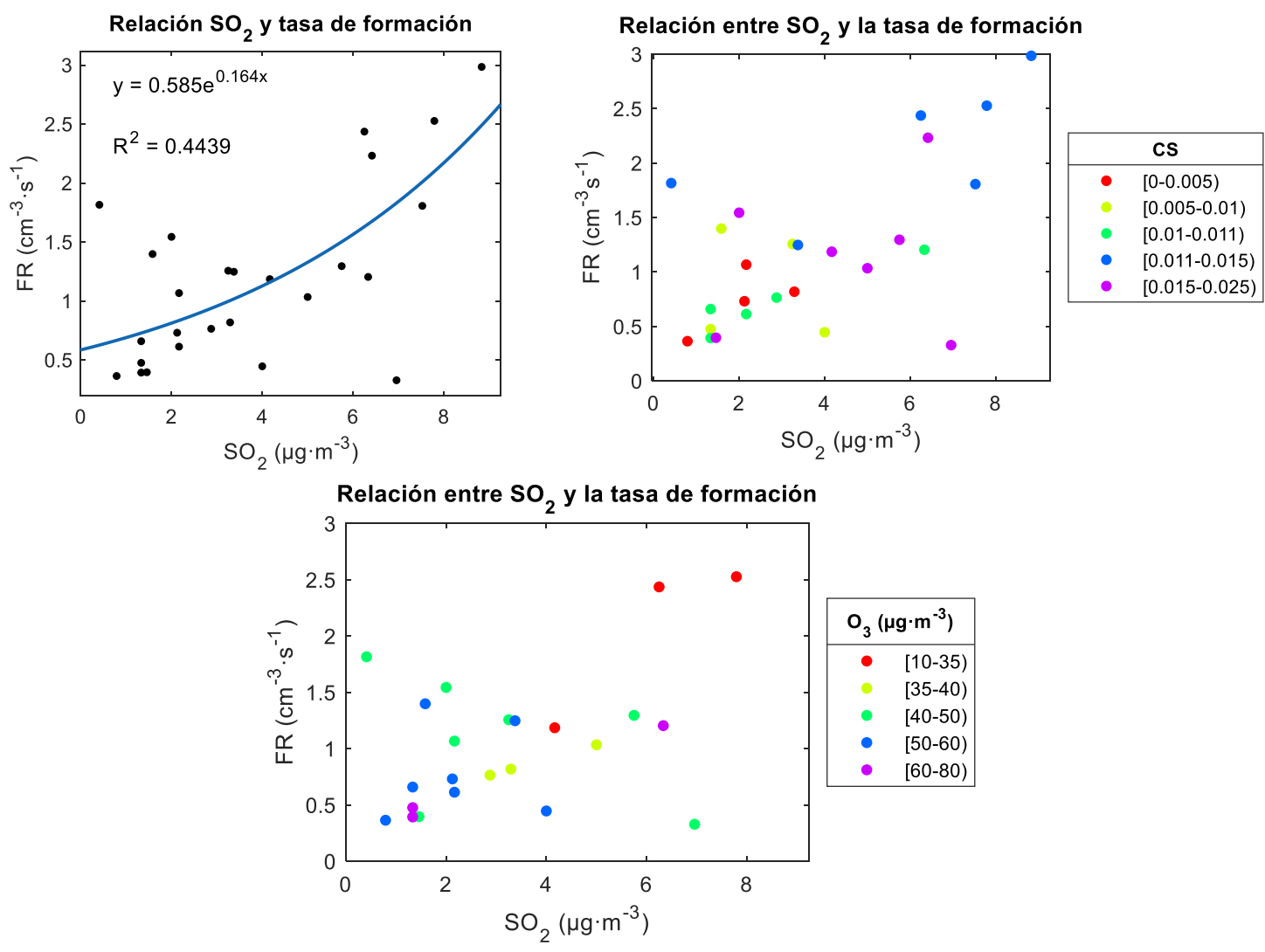

Figura 28. Concentraciones promedio de $\mathrm{SO}_{2}$ frente a la tasa de formación (FR) durante los días de Evento NPF. Izquierda: correlación; derecha: por intervalos del valor del sumidero de condensación (CS); abajo: por intervalos de los valores de la concentración promedio de $\mathrm{O}_{3}$.

En la Figura 29 se muestran las concentraciones promedio de $\mathrm{NO}_{2}$ frente a los valores promedio de la tasa de formación (FR). Se observa una correlación positiva (izquierda) entre ambas variables, indicando así que una mayor concentración de $\mathrm{NO}_{2}$ podría favorecer una mayor formación de partículas, aunque con un peso menor que en el caso del $\mathrm{SO}_{2}$ debido al bajo coeficiente de correlación obtenido. La Figura 29 (derecha) podría mostrar que a una misma concentración de $\mathrm{NO}_{2}$, cuanto mayor sea la concentración de $\mathrm{SO}_{2}$ mayor es la tasa de formación de partículas, aunque esta relación no se cumple en todos los casos.
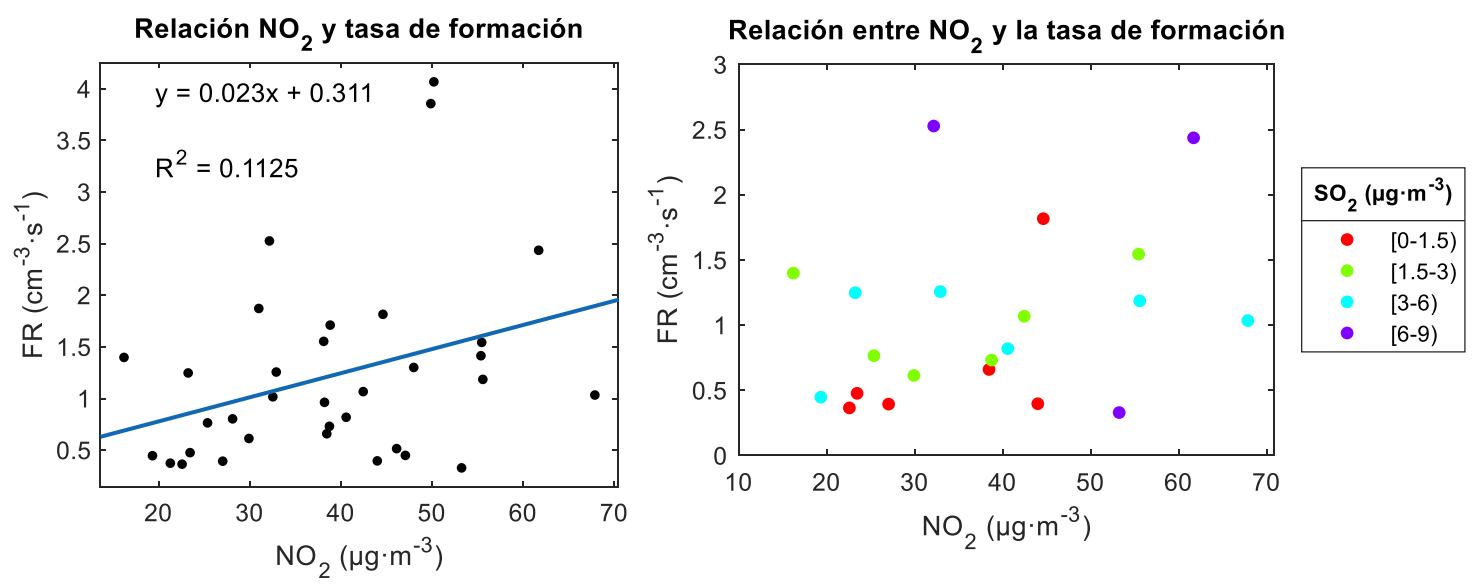

Figura 29. Concentraciones promedio de $\mathrm{NO}_{2}$ frente a la tasa de formación (FR) durante los días de Evento NPF. Izquierda: correlación; derecha: por intervalos de los valores de la concentración promedio de $\mathrm{SO}_{2}$. 
En la Figura 30 se muestran las concentraciones promedio de $\mathrm{O}_{3}$ frente a los valores promedio de la tasa de formación (FR). Se observa que al aumentar el $\mathrm{O}_{3}$ disminuye la tasa de formación. Por otro lado, en la Figura 30 (derecha) se observa una correlación inversa entre las concentraciones de $\mathrm{O}_{3}$ y $\mathrm{NO}_{2}$, ya que a menor concentración de $\mathrm{O}_{3}$ mayor concentración de $\mathrm{NO}_{2}$. Teniendo en cuenta que el $\mathrm{NO}_{2}$ puede considerarse como un gas indicativo de otras emisiones antropogénicas (p. ej., OMS, 2005), y por tanto de gases precursores, estos resultados podrían indicar que, bajo circunstancias de altas concentraciones promedio de $\mathrm{O}_{3}$ y bajas de $\mathrm{NO}_{2}$, las tasas de formación serían bajas debido a las bajas concentraciones de gases precursores.
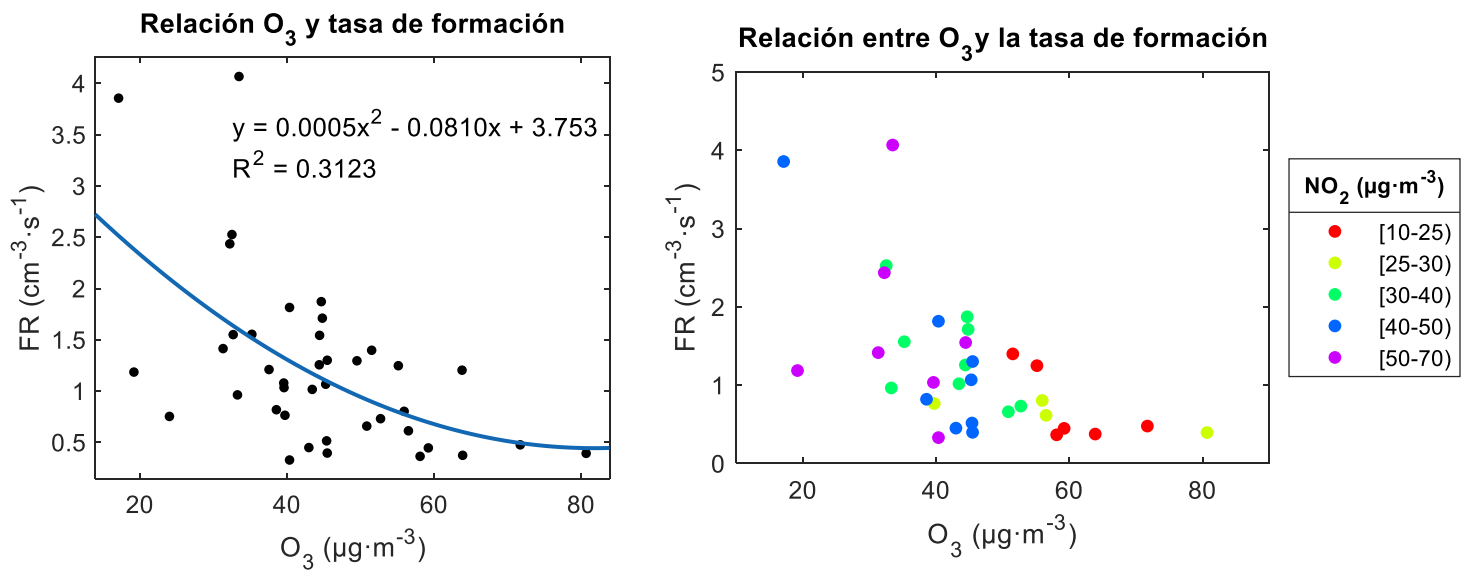

Figura 30. Concentraciones promedio de $\mathrm{O}_{3}$ frente a la tasa de formación (FR) durante los días de Evento NPF. Izquierda: correlación; derecha: por intervalos de los valores de la concentración promedio de $\mathrm{NO}_{2}$.

Siendo el $\mathrm{SO}_{2}$ el principal gas precursor del ácido sulfúrico $\left(\mathrm{H}_{2} \mathrm{SO}_{4}\right)$, algunos estudios (p. ej., Weber et al., 1995, 1996, 1997; Birmili et al., 2003; Kulmala et al., 2006a; Wang et al., 2011) han observado una relación positiva entre la fase gaseosa del $\mathrm{H}_{2} \mathrm{SO}_{4}$ y la tasa de formación de partículas, coincidiendo con los resultados mostrados en este trabajo. Kulmala et al. (2000c) también observó una cierta intervención del amoníaco $\left(\mathrm{NH}_{3}\right)$ en la formación de partículas.

\subsubsection{Estudio de las tasas de crecimiento de partículas}

La Figura 31 muestra una visión general de la relación entre la tasa de crecimiento de las partículas y los parámetros de calidad del aire. Se observa que no existe una correlación clara entre estos parámetros, lo que pone en evidencia el grado de complejidad de este tipo de eventos. 

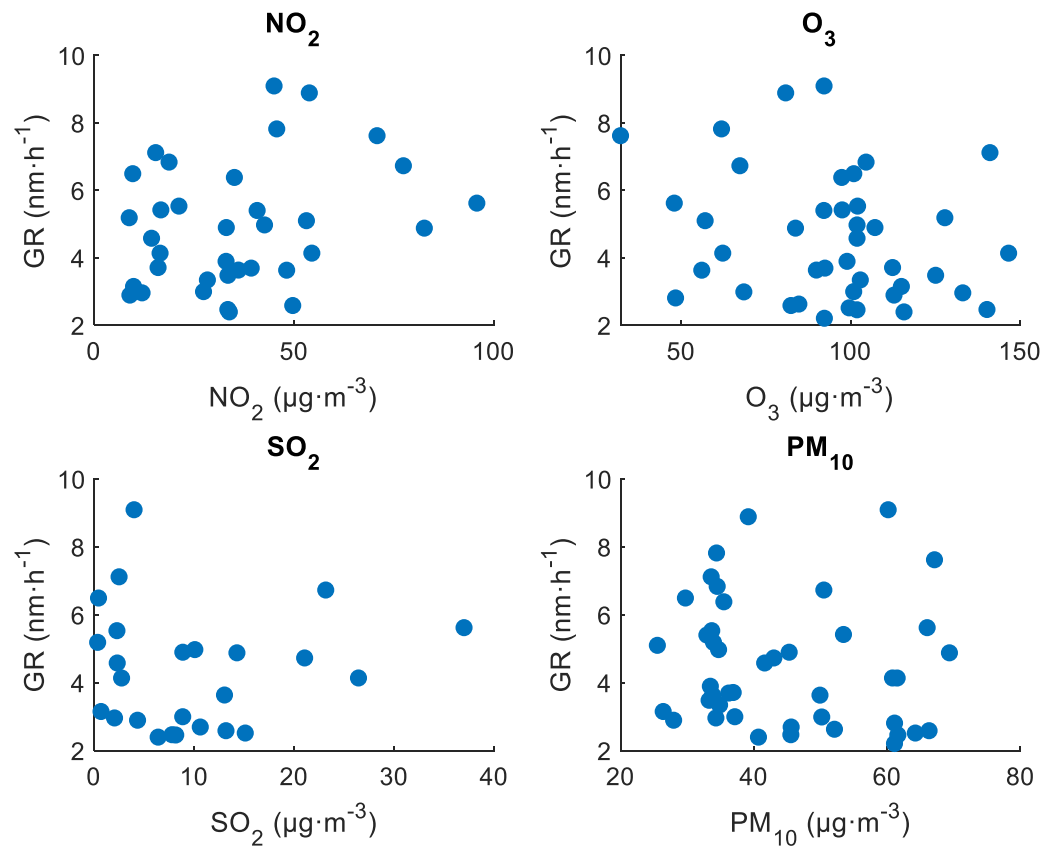

Figura 31. Relación entre la tasa de crecimiento (GR) y los parámetros de calidad del aire $\left(\mathrm{NO}_{2}, \mathrm{O}_{3}, \mathrm{SO}_{2}\right.$ y $\mathrm{PM}_{10}$ ) durante los días de Evento NPF.

La Figura 32 muestra la relación entre la tasa de crecimiento de las partículas y los parámetros de calidad del aire, pero ahora agrupados por intervalos de valores en colores diferentes. En este caso podemos observar la posible asociación entre los parámetros: la tasa de crecimiento depende simultáneamente de los gases $\mathrm{O}_{3}, \mathrm{NO}_{2}$ y $\mathrm{SO}_{2}$, de manera que, a altas concentraciones de ozono, los niveles de dióxido de azufre y de nitrógeno son bajos. Sin embargo, la variación de la combinación de dichos parámetros no se refleja en la variación de la tasa de crecimiento. En cuanto al $\mathrm{PM}_{10}$, en la parte inferior de la Figura 32 , tampoco se observa un patrón claro que condicione la tasa de crecimiento de partículas.

El crecimiento de partículas por condensación de gases de baja volatilidad, que previamente han sido oxidados, se ha mostrado en estudios previos como los de Seinfeld y Pandis (1998). Los precursores de dichos gases son fundamentalmente los compuestos orgánicos volátiles (COVs) (p. ej., Dowd et al., 2002b). En estos estudios se correlacionan los gases no volátiles con oxidantes, como el $\mathrm{O}_{3}, \mathrm{NO}_{2}$ y el radical hidroxilo $(\mathrm{OH})$. Además, (p. ej., Weber et al., 1997; Weber et al., 1998; Birmili et al., 2003) mostraron que el $\mathrm{H}_{2} \mathrm{SO}_{4}$ participa entre un 10 y $30 \%$ en el crecimiento de partículas. En nuestro trabajo, sin embargo, no se han podido comprobar estos resultados. 

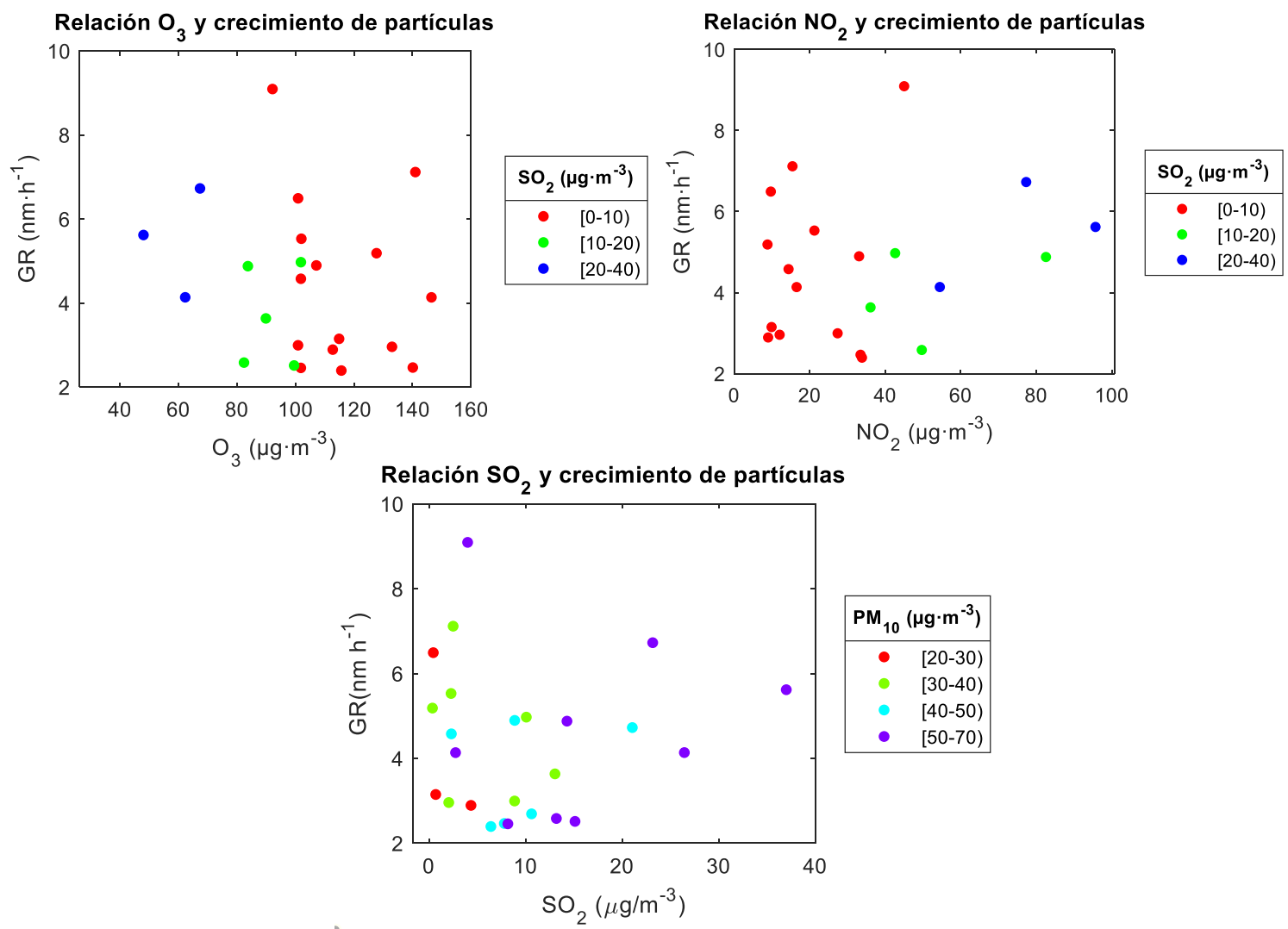

Figura 32. Relación entre la tasa de crecimiento y los parámetros de calidad del aire $\mathrm{NO}_{2}, \mathrm{O}_{3}, \mathrm{SO}_{2}$, agrupados según valores de las concentraciones de $\mathrm{SO}_{2}$ y $\mathrm{PM}_{10}$, durante los días de Evento NPF.

\section{Conclusiones}

En este estudio se realiza una caracterización de los parámetros de calidad del aire medidos en la ciudad de Granada durante el año 2017, en aras al estudio de su relación con los episodios de formación de nuevas partículas (NPF) que pueden producirse a lo largo del año. La evolución temporal de las concentraciones de gases y $\mathrm{PM}_{10}$ queda condicionada fuertemente por la evolución de la altura de la capa de mezcla y los cambios en las fuentes de emisión.

Como resultado, en coincidencia con otros estudios anteriores, las concentraciones de $\mathrm{NO}_{2}$ medidas durante el 2017 son mayores en la estación fría y menores en la estación cálida. Las concentraciones de ozono, en cambio, están fuertemente condicionadas por los niveles de radiación solar en la zona de estudio, observándose mayores concentraciones de este gas en los meses estivales. Las concentraciones de $\mathrm{SO}_{2}$ no presentan una tendencia característica, mientras que las concentraciones de $\mathrm{PM}_{10}$ aumentan en verano debido a la influencia de las intrusiones de polvo procedente del Norte de África y la sequedad del terreno, que producen a su vez fenómenos de resuspensión.

En coincidencia también con otros estudios previos, los resultados muestran que la evolución de las concentraciones de los parámetros de calidad del aire está muy influenciada por las emisiones del tráfico rodado. Semanalmente, evolucionan de la misma manera que lo hace el flujo de vehículos motorizados, con un descenso de las concentraciones en el fin de semana. Diariamente, las concentraciones de $\mathrm{PM}_{10}$ y de $\mathrm{NO}_{2}$ muestran también comportamientos asociados al flujo de tráfico, con los picos 
característicos de la mañana y la tarde. Las concentraciones de $\mathrm{SO}_{2}$ muestran un comportamiento más variable, aunque con un pico en el mediodía. Las concentraciones de $\mathrm{O}_{3}$ están marcadas fundamentalmente por los niveles de radiación solar, mostrando un máximo por la tarde.

Las concentraciones de partículas en la fracción fina (rango de tamaños 12-500 nm), medidas en la estación del IISTA-CEAMA, muestran un comportamiento anual marcado por la evolución del uso de los sistemas de calefacción y de la capa de mezcla, con mayores concentraciones en invierno y menores en verano. El modo predominante fue el modo Aitken, seguido del modo de nucleación y acumulación. También se muestra que el patrón semanal y diario de las concentraciones de partículas está asociado al flujo de tráfico, observándose un descenso general de concentraciones en días no laborables, así como los picos de la mañana y la tarde. Además, se ha observado un tercer pico en los valores de las concentraciones de partículas del modo de nucleación en la estación seca, durante el mediodía, lo cual demuestra que se producen eventos de formación de nuevas partículas.

La clasificación realizada de los eventos NPF ocurridos durante el 2017, marcados por la característica forma de "banana" en las evoluciones temporales de la distribución de tamaños de partículas, ha arrojado que en un 35\% de los días se ha producido este fenómeno. El 12\% se clasificó como Clase I, coincidiendo con los meses de mayor concentración de ozono y niveles de radiación solar, y el $23 \%$ como Clase II. En el período de junio a septiembre, la mayor parte de los días (59\%) se registró como Clase I o Clase II.

Teniendo en cuenta las condiciones en las que se registraron o no episodios de NPF, los días de No Evento han estado marcados por mayores concentraciones de partículas del modo de nucleación y Aitken antes del mediodía, y por mayores concentraciones durante el día completo en el caso del modo de acumulación y $\mathrm{PM}_{10}$. Los valores del sumidero de condensación (CS) también han mostrado valores más altos en los días de No evento respecto a los días de Evento NPF. Este resultado pone de manifiesto que una mayor concentración de partículas preexistentes dificulta la ocurrencia de episodios de NPF.

Los resultados también muestran que existe una posible asociación entre el pico de concentración de partículas del modo de nucleación del mediodía con el pico de $\mathrm{SO}_{2}$. Además, se muestra una correlación positiva entre este gas y la tasa de formación de partículas (FR). Este resultado evidencia el papel del $\mathrm{SO}_{2}$ como gas precursor en la formación de nuevas partículas.

Aunque los resultados muestren mayores concentraciones promedio de $\mathrm{O}_{3}$ y menores de $\mathrm{NO}_{2}$ en los días con eventos frente a los días sin eventos, las relaciones de estos gases con las tasas de formación han sido diferentes. Los resultados ponen de manifiesto que aumentos en las concentraciones de $\mathrm{NO}_{2}$, y descensos en las concentraciones de $\mathrm{O}_{3}$, podrían asociarse con aumentos en los valores de las tasas de formación de nuevas partículas, si bien es cierto que a escala anual los fenómenos de NPF se asocian principalmente con las concentraciones de $\mathrm{O}_{3}$, siendo mayores ambos valores en la estación seca. En cuanto a las tasas de crecimiento de nuevas partículas (GR), no se han encontrado condiciones particulares ni tendencias claras en las concentraciones de gases o partículas que apunten a favorecer o dificultar dicho crecimiento.

Aunque en nuestros resultados se puede observar que el $\mathrm{SO}_{2}$ podría ser un actor principal en los eventos de NPF, es necesario, no obstante, seguir profundizando en estos estudios incluyendo la caracterización de las condiciones atmosféricas y su relación con las concentraciones de partículas y gases, como el $\mathrm{O}_{3}$, cuyo papel podría ser importante, y 
arrojar así más luz sobre las causas que expliquen, entre otras, la variabilidad en las tasas de crecimiento de partículas y, en general, el fenómeno tan influyente en el clima y la salud como es la NPF.

En próximos estudios utilizaremos una base de datos más amplia que pueda ayudar a mejorar las incertidumbres encontradas en este estudio. 


\section{Bibliografía}

Atkinson, R. W., Fuller, G. W., Anderson, H. R., Harrison, R. M., Armstrong, B. (2010). Urban ambient particle metrics and health: A time-series analysis. Epidemiology, 21(4), 501-511. https://doi.org/10.1097/EDE.0b013e3181debc88

Birmili, W., Wiedensohler, A. (2000). New particle formation in the continental boundary layer: Meteorological and gas phase parameter influence. Geophysical Research Letters, 27(20), 3325-3328. https://doi.org/10.1029/1999GL011221

Birmili, W., Berresheim, H., Plass-Dülmer, C., Elste, T., Gilge, S., Wiedensohler, A., Uhrner, U. (2003). The Hohenpeissenberg aerosol formation experiment (HAFEX): A long-term study including size-resolved aerosol, $\mathrm{H} 2 \mathrm{SO} 4, \mathrm{OH}$, and monoterpenes measurements. Atmospheric Chemistry and Physics, 3(2), 361-376. https://doi.org/10.5194/acp-3-361-2003

Boy, M., Kulmala, M. (2002). Nucleation events in the continental boundary layer: Influence of physical and meteorological parameters. Atmospheric Chemistry and Physics, 2(1), 1-16. https://doi.org/10.5194/acp-2-1-2002

Boy, M., Karl, T., Turnipseed, A., Mauldin, R. L., Kosciuch, E., Greenberg, J., Guenther, A. (2008). New particle formation in the front range of the Colorado Rocky Mountains. Atmospheric Chemistry and Physics, 8(6), 1577-1590. https://doi.org/10.5194/acp-8-1577-2008

Carnerero, C., Pérez, N., Reche, C., Ealo, M., Titos, G., Lee, H. K., Querol, X. (2018). Vertical and horizontal distribution of regional new particle formation events in Madrid. Atmospheric Chemistry and Physics, 18(22), 16601-16618. https://doi.org/10.5194/acp-18-16601-2018

Carnerero, C., Pérez, N., Petäjä, T., Laurila, T. M., Ahonen, L. R., Kontkanen, J., Querol, X. (2019). Relating high ozone, ultrafine particles, and new particle formation episodes using cluster analysis. Atmospheric Environment: X, 4(May). https://doi.org/10.1016/j.aeaoa.2019.100051

Casquero-Vera, J. A., Titos, G., Alados-Arboledas, L. (2016). Diagnóstico de la Calidad del Aire del Área Metropolitana de Granada

Casquero-Vera, J. A., Lyamani, H., Titos, G., Borrás, E., Olmo, F. J., AladosArboledas, L. (2019). Impact of primary NO2 emissions at different urban sites exceeding the European NO2 standard limit. Science of the Total Environment, 646(2), 1117-1125. https://doi.org/10.1016/j.scitotenv.2018.07.360

Casquero-Vera, J. A., Lyamani, H., Dada, L., Hakala, S., Paasonen, P., Román, R., Fraile, R., Petäjä, T., Olmo-Reyes, F. J., Alados-Arboledas, L.: New particle formation at urban and high-altitude remote sites in the south-eastern Iberian Peninsula, Atmos. Chem. Phys. Discuss., https://doi.org/10.5194/acp-2020-394, in review, 2020

Castillo, S., Olmo, F.J., Casquero-Vera, J.A., De Arruda Moreira, G., Lyamani, H., Titos, G., Muñoz, C., Quirantes, A., Rejano, F., Alados, I., Alados-Arboledas, L. Air quality at different temporal scales in a non-industrialized city influenced by the local topography. Submitted, 2020

Ceballos, M. Á., Segura, P., Blázquez, N., Gutiérrez, E., Gracia, J. C., Ramos, P., Hernández, K. (2017). La calidad del aire en el Estado español durante 2017. Retrieved from https://www.ecologistasenaccion.org/?p=97539 
Colbeck, I., Lazaridis, M. (2014). Aerosol Science: Technology and Applications. John Wiley \& Sons Ltd

Dada, L., Paasonen, P., Nieminen, T., Buenrostro Mazon, S., Kontkanen, J., Peräkylä, O., Kulmala, M. (2017). Long-term analysis of clear-sky new particle formation events and nonevents in Hyytiälä. Atmospheric Chemistry and Physics, 17(10), 6227-6241. https://doi.org/10.5194/acp-17-6227-2017

Dal Maso, M., Kulmala, M., Riipinen, I., Wagner, R., Hussein, T., Aalto, P. P., Lehtinen, K. E. J. (2005). Formation and growth of fresh atmospheric aerosols: Eight years of aerosol size distribution data from SMEAR II, Hyytiälä, Finland. Boreal Environment Research, 10(5), 323-336

Dal Maso, M., Sogacheva, L., Aalto, P. P., Riipinen, I., Komppula, M., Tunved, P., Kulmala, M. (2007). Aerosol size distribution measurements at four Nordic field stations: Identification, analysis and trajectory analysis of new particle formation bursts. Tellus, Series B: Chemical and Physical Meteorology, 59(3), 350-361. https://doi.org/10.1111/j.1600-0889.2007.00267.x

Dall'Osto, M., Beddows, D. C. S., Asmi, A., Poulain, L., Hao, L., Freney, E., Harrison, R. M. (2018). Novel insights on new particle formation derived from a paneuropean observing system. Scientific Reports, 8(1), 1-11. https://doi.org/10.1038/s41598-017-17343-9

De Arruda Moreira, G., Guerrero-Rascado, J. L., Bravo-Aranda, J. A., Foyo, I., Cazorla, A., Alados, I., Lyamani, H., Landulfo, E., Alados-Arboledas, L., 2020. Study of the Planetary Boundary Layer Height in an urban environment using a combination of microwave radiometer and ceilometer. Atmos. Res. 240, 104932. https://doi.org/10.1016/j.atmosres.2020.104932

Fernández-Camacho, R., Rodríguez, S., De La Rosa, J., Sánchez De La Campa, A. M., Viana, M., Alastuey, A., Querol, X. (2010). Ultrafine particle formation in the inland sea breeze airflow in Southwest Europe. Atmospheric Chemistry and Physics, 10(19), 9615-9630. https://doi.org/10.5194/acp-10-9615-2010

Fuchs, N.A., Sutugin, A.G. (1970). Highly dispersed aerosols. Ann Arbour Science Publishers, Ann Arbour, London

Gordon, H., Kirkby, J., Baltensperger, U., Bianchi, F., Breitenlechner, M., Curtius, J., Carslaw, K. S. (2017). Causes and importance of new particle formation in the present-day and preindustrial atmospheres. Journal of Geophysical Research: Atmospheres, 122(16), 8739-8760. https://doi.org/10.1002/2017JD026844

Hussein, T., Dal Maso, M., Petäjä, T., Koponen, I. K., Paatero, P., Aalto, P. P., Kulmala, M. (2005). Evaluation of an automatic algorithm for fitting the particle number size distributions. Boreal Environment Research, 10(5), 337-355.

Intergovernmental Panel on Climate Change. (2014). Climate Change 2013 - The Physical Science Basis: Working Group I Contribution to the Fifth Assessment Report of the Intergovernmental Panel on Climate Change. Cambridge, United Kinkdom: Cambridge University Press

Kanawade, V. P., Jobson, B. T., Guenther, A. B., Erupe, M. E., Pressley, S. N., Tripathi, S. N., Lee, S. H. (2011). Isoprene suppression of new particle formation in a mixed deciduous forest. Atmospheric Chemistry and Physics, 11(12), 6013-6027. https://doi.org/10.5194/acp-11-6013-2011

Kerminen, V. M., Chen, X., Vakkari, V., Petäjä, T., Kulmala, M., Bianchi, F. (2018). 
Atmospheric new particle formation and growth: Review of field observations.

Environmental Research Letters, 13(10). https://doi.org/10.1088/1748-9326/aadf3c

Koulouri, E., Saarikoski, S., Theodosi, C., Markaki, Z., Gerasopoulos, E., Kouvarakis, G., Mäkelä, T., Hillamo, R., Mihalopoulos, N. (2008). Chemical composition and sources of fine and coarse aerosol particles in the Eastern Mediterranean.

Atmospheric Environment. 42, 6542-6550. doi:10.1016/j.atmosenv.2008.04.010

Kulmala, M., Pirjola, L., Mäkelä, J. M. (2000). Stable sulphate clusters as a source of new atmospheric particles. Nature, 404(6773), 66-69. https://doi.org/10.1038/35003550

Kulmala, M., Dal Maso, M., Mäkelä, J. M., Pirjola, L., Väkevä, M., Aalto, P., O’Dowd, C. D. (2001). On the formation, growth and composition of nucleation mode particles. Tellus, Series B: Chemical and Physical Meteorology, 53(4), 479-490. https://doi.org/10.3402/tellusb.v53i4.16622

Kulmala, M., Vehkamäki, H., Petäjä, T., Dal Maso, M., Lauri, A., Kerminen, V. M., McMurry, P. H. (2004). Formation and growth rates of ultrafine atmospheric particles: A review of observations. Journal of Aerosol Science, 35(2), 143-176. https://doi.org/10.1016/j.jaerosci.2003.10.003

Kulmala, M., Petäjä, T., Nieminen, T., Sipilä, M., Manninen, H. E., Lehtipalo, K., Dal Maso, M., Aalto, P. P., Junninen, H., Paasonen, P., Riipinen, I., Lehtinen, K. E. J., Laaksonen, A., Kerminen, V. M. (2012). Measurement of the nucleation of atmospheric aerosol particles. Nature Protocols, 7(9), 1651-1667. https://doi.org/10.1038/nprot.2012.091

Kulmala, M., Kerminen, V.-M., Petäjä, T., Ding, A. J., Wang, L. (2017). Atmospheric gas-to-particle conversion: why NPF events are observed in megacities? Faraday Discussions, 200, 271-288. https://doi.org/10.1039/c6fd00257a

Lanzinger, S., Schneider, A., Breitner, S., Stafoggia, M., Erzen, I., Dostal, M., Mykhalchuk, B. (2016). Associations between ultrafine and fine particles and mortality in five central European cities - Results from the UFIREG study. Environment International, 88(January 2016), 44-52. https://doi.org/10.1016/j.envint.2015.12.006

Lyamani, H., Olmo, F. J., Alados-Arboledas, L. (2005). Saharan dust outbreak over southeastern Spain as detected by sun photometer. Atmospheric Environment, 39(38), 7276-7284. https://doi.org/10.1016/j.atmosenv.2005.09.011

Lyamani, H., Olmo, F. J., Alados-Arboledas, L. (2010). Physical and optical properties of aerosols over an urban location in Spain: Seasonal and diurnal variability. Atmospheric Chemistry and Physics, 10(1), 239-254. https://doi.org/10.5194/acp10-239-2010

Lyamani, H., Olmo, F. J., Alca, A. (2006). Atmospheric aerosols during the 2003 heat wave in southeastern Spain I: Spectral optical depth. 40, 6453-6464. https://doi.org/10.1016/j.atmosenv.2006.04.048

Lyamani, H., Olmo, F. J., Foyo, I., Alados-Arboledas, L. (2011). Black carbon aerosols over an urban area in south-eastern Spain: Changes detected after the 2008 economic crisis. Atmospheric Environment, 45(35), 6423-6432. https://doi.org/10.1016/j.atmosenv.2011.07.063

Mészáros, E. (1999). Fundamentals of Atmospheric Aerosol Chemistry.Akademiai Kiado 
Ministerio para la Transición Ecológica. (2017). Evaluación de la Calidad del Aire en España

Monks, P. S., Archibald, A. T., Colette, A., Cooper, O., Coyle, M., Derwent, R., Williams, M. L. (2015). Tropospheric ozone and its precursors from the urban to the global scale from air quality to short-lived climate forcer. Atmospheric Chemistry and Physics, 15(15), 8889-8973. https://doi.org/10.5194/acp-15-88892015

Morawska, L., Ristovski, Z., Jayaratne, E. R., Keogh, D. U., Ling, X. (2008). Ambient nano and ultrafine particles from motor vehicle emissions: Characteristics, ambient processing and implications on human exposure. Atmospheric Environment, 42(35), 8113-8138. https://doi.org/10.1016/j.atmosenv.2008.07.050

O’Dowd, C. D., Aalto, P., Hämeri, K., Kulmala, M., Hoffmann, T. (2002). Atmospheric particles from organic vapours. Nature, 416(6880), 497-498.

https://doi.org/10.1038/416497a

Olmo, F. J., Quirantes, A., Alcántara, A., Lyamani, H., Alados-Arboledas, L. (2006). Preliminary results of a non-spherical aerosol method for the retrieval of the atmospheric aerosol optical properties. Journal of Quantitative Spectroscopy and Radiative Transfer, 100(1-3), 305-314. https://doi.org/10.1016/j.jqsrt.2005.11.047

Olmo, F. J., Quirantes, A., Lara, V., Lyamani, H., Alados-Arboledas, L. (2008). Aerosol optical properties assessed by an inversion method using the solar principal plane for non-spherical particles. Journal of Quantitative Spectroscopy and Radiative Transfer, 109(8), 1504-1516. https://doi.org/10.1016/j.jqst.2007.12.019

Organización Mundial de la Salud. (2005). Guías de calidad del aire de la OMS relativas al material particulado, el ozono, el dióxido de nitrógeno y el dióxido de azufre. Actualización mundial 2005. https://apps.who.int/iris/bitstream/handle/10665/69478/WHO_SDE_PHE_OEH_0 6.02_spa.pdf;jsessionid=E80C2605DFB1E4C21729FD2AA1FCDC67? sequence= 1

Pandolfi, M., Alados-Arboledas, L., Alastuey, A., Andrade, M., Angelov, C., Artiñano, B., Laj, P. (2018). A European aerosol phenomenology - 6: Scattering properties of atmospheric aerosol particles from 28 ACTRIS sites. Atmospheric Chemistry and Physics, 18(11), 7877-7911. https://doi.org/10.5194/acp-18-7877-2018

Pey, J., Querol, X., Alastuey, A., Rodríguez, S., Putaud, J. P., Van Dingenen, R. (2009). Source apportionment of urban fine and ultra-fine particle number concentration in a Western Mediterranean city. Atmospheric Environment, 43(29), 4407-4415. https://doi.org/10.1016/j.atmosenv.2009.05.024

Qian, S., Sakurai, H., McMurry, P. H. (2007). Characteristics of regional nucleation events in urban East St. Louis. Atmospheric Environment, 41(19), 4119-4127. https://doi.org/10.1016/j.atmosenv.2007.01.011

Querol, X., Alastuey, A., Puicercus, J. A., Mantilla, E., Miro, J. V., Lopez-Soler, A., Artiñano, B. (1998). Seasonal evolution of suspended particles around a large coalfired power station: Particulate levels and sources. Atmospheric Environment, 32(11), 1963-1978. https://doi.org/10.1016/S1352-2310(97)00504-9

Querol, X., Alastuey, A., Gangoiti, G., Perez, N., Lee, H. K., Eun, H. R., Ahn, K. H. (2018). Phenomenology of summer ozone episodes over the Madrid Metropolitan Area, central Spain. Atmospheric Chemistry and Physics, 18(9), 6511-6533. 
https://doi.org/10.5194/acp-18-6511-2018

Rodríguez, S., Querol, X., Alastuey, A., Kallos, G., Kakaliagou, O. (2001). Saharan dust contributions to PM10 and TSP levels in Southern and Eastern Spain. Atmospheric Environment, 35(14), 2433-2447. https://doi.org/10.1016/S13522310(00)00496-9

Rodríguez, S., Van Dingenen, R., Putaud, J. P., Dell'Acqua, A., Pey, J., Querol, X., Gemelli, V. (2007). A study on the relationship between mass concentrations, chemistry and number size distribution of urban fine aerosols in Milan, Barcelona and London. Atmospheric Chemistry and Physics, 7(9), 2217-2232. https://doi.org/10.5194/acp-7-2217-2007

Salma, I., Borsòs, T., Weidinger, T., Aalto, P., Hussein, T., Dal Maso, M., Kulmala, M. (2011). Production, growth and properties of ultrafine atmospheric aerosol particles in an urban environment. Atmospheric Chemistry and Physics, 11(3), 1339-1353. https://doi.org/10.5194/acp-11-1339-2011

Salma, Imre, Németh, Z., Kerminen, V. M., Aalto, P., Nieminen, T., Weidinger, T., Kulmala, M. (2016). Regional effect on urban atmospheric nucleation.

Atmospheric Chemistry and Physics, 16(14), 8715-8728. https://doi.org/10.5194/acp-16-8715-2016

Secretaría de Medio Ambiente y Desarrollo Sustentable, J. (2012). Informe De Calidad Del Aire 2011

Sorribas, M.M. (2007). Medida y caracterización del aerosol atmosférico en un ambiente rural y costero del suroeste de europa. La distribución numérica de tamaños en el rango sub-micrométrico (tesis doctoral). Universidad de Valladolid

Spracklen, D. V., Carslaw, K. S., Kulmala, M., Kerminen, V. M., Mann, G. W., Sihto, S. L. (2006). The contribution of boundary layer nucleation events to total particle concentrations on regional and global scales. Atmospheric Chemistry and Physics, 6(12), 5631-5648. https://doi.org/10.5194/acp-6-5631-2006

Titos, G., Foyo-Moreno, I., Lyamani, H., Querol, X., Alastuey, A., Alados-Arboledas, L. (2012). Optical properties and chemical composition of aerosol particles at an urban location: An estimation of the aerosol mass scattering and absorption efficiencies. Journal of Geophysical Research Atmospheres, 117(4), 1-12. https://doi.org/10.1029/2011JD016671

Titos, G., Jefferson, A., Sheridan, P. J., Andrews, E., Lyamani, H., Alados-Arboledas, L., Ogren, J. A. (2014). Aerosol light-scattering enhancement due to water uptake during the TCAP campaign. Atmospheric Chemistry and Physics, 14(13), 70317043. https://doi.org/10.5194/acp-14-7031-2014

Tobías, A., Rivas, I., Reche, C., Alastuey, A., Rodríguez, S., Fernández-Camacho, R., Querol, X. (2018). Short-term effects of ultrafine particles on daily mortality by primary vehicle exhaust versus secondary origin in three Spanish cities.

Environment International, 111(August 2017), 144-151.

https://doi.org/10.1016/j.envint.2017.11.015

Valenzuela, A., Olmo, F. J., Lyamani, H., Antón, M., Quirantes, A., Alados-Arboledas, L. (2012a). Aerosol radiative forcing during African desert dust events (20052010) over Southeastern Spain. Atmospheric Chemistry and Physics, 12(21), 10331-10351. https://doi.org/10.5194/acp-12-10331-2012

Valenzuela, A., Olmo, F. J., Lyamani, H., Antón, M., Quirantes, A., Alados-Arboledas, 
L. (2012b). Classification of aerosol radiative properties during African desert dust intrusions over southeastern Spain by sector origins and cluster analysis. Journal of Geophysical Research Atmospheres, 117(6).

https://doi.org/10.1029/2011JD016885

Wang, Z. B., Hu, M., Yue, D. L., Zheng, J., Zhang, R. Y., Wiedensohler, A., Boy, M. (2011). Evaluation on the role of sulfuric acid in the mechanisms of new particle formation for Beijing case. Atmospheric Chemistry and Physics, 11(24), 1266312671. https://doi.org/10.5194/acp-11-12663-2011

Wang, D., Zhou, B., Fu, Q., Zhao, Q., Zhang, Q., Chen, J., Li, J. (2016). Intense secondary aerosol formation due to strong atmospheric photochemical reactions in summer: observations at a rural site in eastern Yangtze River Delta of China. Science of the Total Environment, 571, 1454-1466. https://doi.org/10.1016/j.scitotenv.2016.06.212

Weber, R. J., Marti, J. J., McMurry, P. H., Eisele, F. L., Tanner, D. J., Jefferson, A. (1997). Measurements of new particle formation and ultrafine particle growth rates at a clean continental site. Journal of Geophysical Research Atmospheres, 102(4), 4375-4385. https://doi.org/10.1029/96jd03656

Weber, Rodney J., McMurry, P. H., Mauldin, L., Tanner, D. J., Eisele, F. L., Brechtel, F. J., Baumgardner, B. (1998). A study of new particle formation and growth involving biogenic and trace gas species measured during ACE 1. Journal of Geophysical Research Atmospheres, 103(D13), 16385-16396. https://doi.org/10.1029/97JD02465

Wiedensohler, A., Birmili, W., Nowak, A., Sonntag, A., Weinhold, K., Merkel, M., Bastian, S. (2012). Mobility particle size spectrometers: Harmonization of technical standards and data structure to facilitate high quality long-term observations of atmospheric particle number size distributions. Atmospheric Measurement Techniques, 5(3), 657-685. https://doi.org/10.5194/amt-5-657-2012

Wonaschütz, A., Demattio, A., Wagner, R., Burkart, J., Zíková, N., Vodička, P., Hitzenberger, R. (2015). Seasonality of new particle formation in Vienna, Austria Influence of air mass origin and aerosol chemical composition. Atmospheric Environment, 118, 118-126. https://doi.org/10.1016/j.atmosenv.2015.07.035

Wu, Z., Hu, M., Liu, S., Wehner, B., Bauer, S., Ma ßLing, A., Kulmala, M. (2007). New particle formation in Beijing, China: Statistical analysis of a 1-year data set. Journal of Geophysical Research Atmospheres, 112(9), 1-10. https://doi.org/10.1029/2006JD007406

Yu, F., Luo, G., Bates, T. S., Anderson, B., Clarke, A., Kapustin, V., Wu, S. (2010). Spatial distributions of particle number concentrations in the global troposphere: Simulations, observations, and implications for nucleation mechanisms. Journal of Geophysical Research Atmospheres, 115(17). https://doi.org/10.1029/2009JD013473 